
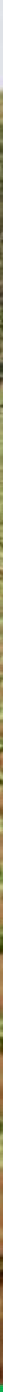

Coping with price risks on Dutch farms

Marcel van Asseldonk and Ruud van der Meer

LE I

WAGENINGEN UR 



\section{Coping with price risks on Dutch farms}

Marcel van Asseldonk and Ruud van der Meer 
Marcel van Asseldonk and Ruud van der Meer, 2016. Coping with price risks on Dutch farms. Wageningen, LEI Wageningen UR (University \& Research centre), LEI Report 2016-054. 30 pp.; 26 fig.; 0 tab.; 15 ref.

Output price fluctuations are the main reason for volatile family farm incomes. Adoption of risk management strategies to cope with income volatility in agriculture differs between sectors in agriculture. Uptake of price contracts is a common practice applied on Dutch arable farms.

Approximately $50 \%$ of the Dutch arable farmers have some kind of potato price contract of which the pool contracts and fixed price contracts are the most common ones. In all other sectors the availability and uptake of price contracts has hardly been established.

This report can be downloaded for free at http://dx.doi.org/10.18174/382697 or at www.wageningenUR.nl/en/lei (under LEl publications).

(C) 2016 LEI Wageningen UR

P.O. Box 29703, 2502 LS The Hague, The Netherlands, T +31 (0)7033583 30,

E informatie.lei@wur.nl, www.wageningenUR.nl/en/lei. LEl is part of Wageningen UR (University \& Research centre).

\section{(cc) BY-NC}

For its reports, LEI utilises a Creative Commons Attributions 3.0 Netherlands license.

(C) LEI , part of DLO Foundation, 2016

The user may reproduce, distribute and share this work and make derivative works from it. Material by third parties which is used in the work and which are subject to intellectual property rights may not be used without prior permission from the relevant third party. The user must attribute the work by stating the name indicated by the author or licensor but may not do this in such a way as to create the impression that the author/licensor endorses the use of the work or the work of the user. The user may not use the work for commercial purposes.

LEI accepts no liability for any damage resulting from the use of the results of this study or the application of the advice contained in it.

LEI is ISO $9001: 2008$ certified.

LEI 2016-054 | Project code 2282300149

Cover photo: Shutterstock 


\section{Contents}

$\begin{array}{ll}\text { Preface } & 4\end{array}$

$\begin{array}{ll}\text { Summary } & 5\end{array}$

S.1 Key findings $\quad 5$

S.2 Complementary results $\quad 5$

$\begin{array}{lll}\text { S.3 Method } & 6\end{array}$

$\begin{array}{ll}\text { Introduction } & 7\end{array}$

2

$\begin{array}{ll}\text { Data analysis } & \mathbf{8}\end{array}$

2.1 Panel data $\quad 8$

2.2 Volatility of key inputs and outputs $\quad 8$

2.3 Resilience $\quad 9$

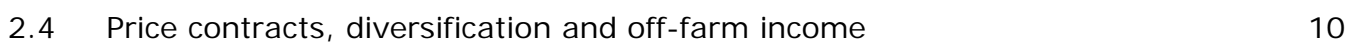

3.1 Volatility and resilience in the arable crops sector 11

3.2 Volatility and resilience in the horticulture sector $\quad 13$

$\begin{array}{lll}3.3 & \text { Volatility and resilience in the dairy sector } & 14\end{array}$

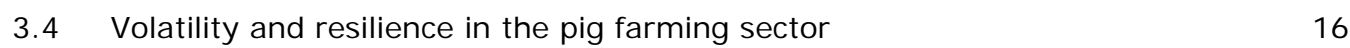

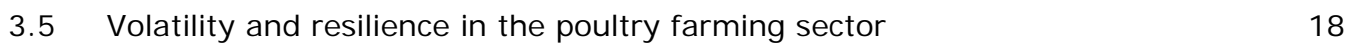

4.1 Risk management strategies in the arable crops sector 20

4.2 Risk management strategies in the greenhouse horticulture sector $\quad 21$

$\begin{array}{lll}4.3 & \text { Risk management strategies in the dairy sector } & 22\end{array}$

4.4 Risk management strategies in the pig sector 23

$\begin{array}{lll}4.5 & \text { Risk management strategies in the poultry sector } & 24\end{array}$

5.1 Volatility and resilience $\quad 26$

5.2 Adoption and impact of risk management strategies $\quad 26$

$\begin{array}{lr}\text { References } & \mathbf{2 8}\end{array}$ 


\section{Preface}

This report provides an analysis of income volatility and risk management strategies applied in Dutch agriculture. This topic is of increasing interest for farmers as well as for policy makers. Besides production related risks (e.g. weather perils), instability of agricultural markets and fluctuations of the prices received by farmers are major reasons for the volatility of incomes in the farm sector. Several risk management strategies adopted by farmers to cope with risks are analysed. These strategies include on-farm measures such as diversification, as well as strategies for sharing risk with others by using contracts, or by off-farm employment.

We express our thanks to the Dutch Ministry of Economic affairs for its financial support, and in particular we thank Henk Riphagen and Elselien Breman for their valuable comments.

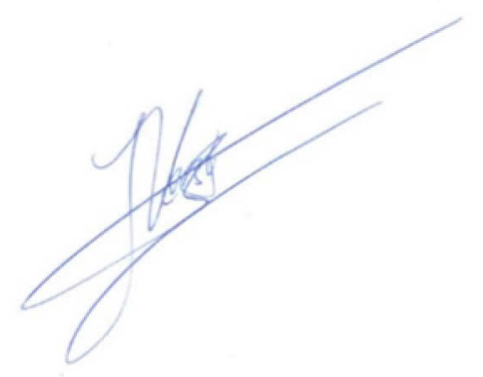

Prof. dr. ir. Jack (J.G.A.J.) van der Vorst General Director Social Sciences Group Wageningen UR 


\section{Summary}

\section{S.1 Key findings}

Instability of agricultural markets, and fluctuations of prices received by farmers, are major reasons for volatile family farm incomes. As illustrated in this report, there are large differences in volatility, and resilience, between Dutch agricultural sectors in the period 2001-2014. Also with a standardised measure for volatility, substantial heterogeneity was observed between farms within the same sector. The granivore sector (pigs and poultry) and the greenhouse horticulture sector are sectors with the largest fluctuations in family farm incomes. Volatility in family farm income was relatively low in the arable sector. In the dairy sector family farm income was even more smoothened, but projections are that now the EU milk quota system has been abolished, dairy farmers are becoming more exposed to the world market for dairy products and are becoming more vulnerable to (supply and demand) shocks affecting dairy markets and prices.

Adoption and impact of risk management strategies to cope with income volatility in agriculture differs between sectors analysed. Uptake of price contracts is a common practice applied on Dutch arable farms. Approximately $50 \%$ of the Dutch arable farmers have some kind of potato price contract of which the pool contracts and fixed price contracts are the most common ones. In all other sectors analysed the availability and uptake of price contracts has hardly been established. On average, and in relative terms, off-farm incomes as a risk management strategy smoothens household income only in a limited degree for typical, and thus specialised, Dutch farms. Furthermore, diversification is only applied to a limited degree on these specialised farms with the exception of arable farms.

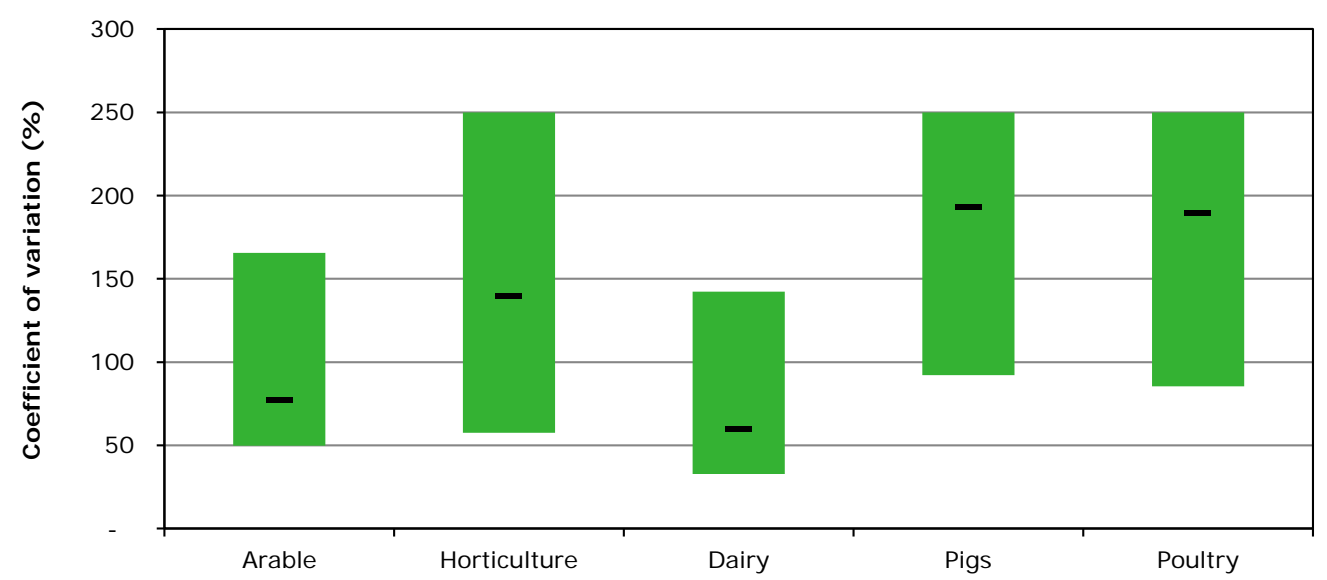

Figure S.1 Coefficient of variation of family farm income (median, 20 percentile value and 80 percentile value).

\section{S.2 Complementary results}

Despite free market conditions and volatile prices in most sectors (i.e., pigs, poultry and horticulture) and as the EU dairy sector is now emerging into a more free market situation, the market has not evolved over time in offering farmers effective price contracts. 
In general, risk management strategies enable to smoothen or enhance income in the farming sectors. The availability of effective risk management strategies (e.g. price contracts for potatoes) opens opportunities for farmers to engage other risks (i.e., specialisation or increasing farm size). Effective strategies that reduce price risks will ultimately increase farmers utility (which does not necessarily manifests itself in a reduced CV of family farm income).

\section{S.3 Method}

The assessment presented in this study is based on panel data analysis, using a sample of Dutch agricultural farms included in the Farm Accountancy Data Network (FADN) and Innovation Monitor (IM) of the LEI Wageningen UR in the Netherlands. The coefficient of variation (CV) is used as a proxy for family farm income volatility. Resilience is specified as the percentage of farms that will suffer from a worsening continuity perspective (or possible bankruptcy) due to a price or revenue decrease as a consequence of a possible crisis (i.e., 30\% reduction). 


\section{$1 \quad$ Introduction}

Income volatility and risk management strategies to cope with income volatility in agriculture is a topic of increasing interest for farmers as well as for policy makers. Besides production-related risks (e.g. weather perils), instability of agricultural markets and fluctuations of the prices received by farmers are major reasons for volatile incomes (Vrolijk and Poppe, 2008). Several risk management strategies can be adopted by farmers to cope with risks. These strategies include on-farm measures such as diversification or off-farm income, as well as strategies for sharing risk with others by using price contracts.

Farms were in the past typically set up as diversified multi-commodity operations. While this may partly be based on agronomic grounds, it likewise has important impacts on the risk exposure. For most cases the net returns from agricultural production activities are positively correlated, mainly because of the correlation of commodity prices. Also weather conditions during a growing season may affect crop yields similarly. However, since these correlations are only moderate, significant diversification effects may occur. The portfolio risk decreases as the number of produced commodities increases, however, at diminishing rates (Berg et al., 2007).

It is important to consider that many of the farms combine agriculture with other economic activities (either non-agricultural forms of production on the holding, or off-farm employment, or income from financial and real estate assets). Thus off-farm income is a diversification strategy to manage risks at household level since off-farm income is independent, or weakly correlated, from those stemming from agricultural activities.

Farmers can manage price risk by initiating a forward contract with buyers and input suppliers. With such a contract they agree on for example the price, quantity, quality, location and date of delivery. In contrast to futures contracts, these instruments are not centrally traded and are not standardised. In general, forward contracts in agriculture are price-pooling arrangements operated through a group of farmers who collectively buy their inputs or sell their outputs through a cooperative or marketing board (Anderson, 2003). The price pooling arrangements may be operated in various ways but are generally designed to protect the individual from short-term fluctuations in prices by some form of averaging. Pooling contracts impact both mean and variance of the price received, and their efficacy to mitigate the negative effects of price variability depends on the type of contract under consideration. Of course farmer's income will still be uncertain because of the inherent yield risk (Smidts, 1990).

An important first step is to develop an understanding of the stability, or lack of stability, in farm incomes. Moreover, the impact of adopted risk management strategies is essential to understand the observed difference in volatility between farms. However, the empirical evidence for trade-offs between risk and return of adopted risk management strategies is still very scarce. The objective of this report is to develop an understanding of the volatility in farm incomes and the adoption (and impact) of risk management strategies in Dutch agriculture. More specifically, the objectives are:

- to analyse individual farm data with respect to (input/output) price, production and farm income volatility

- to determine the financial resilience of farm households

- to provide insight into adoption (and impact) of risk management strategies (i.e., use of price contracts, off-farm income and diversification). 


\section{Data analysis}

\subsection{Panel data}

A descriptive panel data analysis is conducted to analyse the heterogeneity of volatility of key variables (i.e., yield, price, and farm income) per sector (i.e., arable, greenhouse horticulture, dairy, pigs and poultry). Furthermore, heterogeneity of financial resilience is quantified for farm cash flows over time. The panel data also enables to monitor and evaluate the level of risk management strategies adopted (i.e., price contracts, diversification and off-farm income).

The cases used in this study were derived from a sample of Dutch agricultural farms included in the Farm Accountancy Data Network (FADN) and Innovation Monitor (IM) of the Agricultural Economics Research Institute (LEI) in the Netherlands (Diederen et al., 2003; Lans et al., 2014). This is a representative sample of the agricultural sector in the Netherlands. Specialised farms were selected for each sector analysed only from this stratified sample if at least $67 \%$ of the standard gross margin originated from the main activity (Vrolijk et al., 2010). Although mixed farming with diversification as risk management strategy is considered very effective, the adoption in Dutch agriculture is limited because it hampers efficiency of scale (and thus limits prospects of higher average incomes). Only 3\% of all farms are mixed farm types (combining livestock with crops, or combining different livestock species). Measured in Standard Output (SO), mixed farms also account for 3\% of total SO. SO is the average monetary value of the agricultural output at farm-gate price of each agricultural product. The specialised farms could however apply diversification within each subsector (e.g., different crops on arable farms).

The analysed sample consisted of 2,126 firms. Annual data from an unbalanced panel for the period 2001-2014 were used. Farms participate in the panel on average for 7 years. Off-farm income is only recorded for a sub-sample. With respect to price contracts, which are part of the Innovation Monitor, data were only available for four consecutive years (2009-2012). This short time period hampers a robust impact assessment since a longer time horizon capturing the full distribution of spot market and contract prices in adverse and favourable years is a prerequisite.

\subsection{Volatility of key inputs and outputs}

Nominal family farm income is used as the key measure (hence referred to as farm income). Farm income is calculated by deducting the incurred costs and depreciation from the total operating income and then adding the balance of the extraordinary income and expenditure. Furthermore, underlying variables with regard to price and production risk were identified using a family farm income analysis scheme. Included were gross margin, revenue, price of inputs and outputs, and yield per main activity (i.e., crop or livestock species).

Given the wide range of incomes between farms in each year, and the changes in average and median incomes in subsequent years, this raises the question whether farmers simultaneously move up and down following the trend or that farmers change their relative performance compared to their peers. The latter would mean that farmers are confronted with even higher fluctuations in incomes at farm level. From a farmer's perspective, the changes in farm income on an individual farm is the most important fluctuation. It reflects the uncertainty a farmer has to cope with. The question arises whether farms in the lower percentiles of the income distribution during a certain year are 'trapped' in this low income category or, phrased otherwise: Do farms in the lowest quintile of incomes in a certain year stay in the lower quintile in the next year or can they improve their (relative) income position by moving to another quintile? Therefore, the probability of being trapped in a certain income category is analysed per sector. 
The coefficient of variation (CV) is used as a proxy for volatility. The coefficient of variation is a standardised measure of dispersion. It is often expressed as a percentage, and is defined as the ratio of the standard deviation to the mean (or its absolute value). By doing so, it allows for meaningful comparison between two or more magnitudes of variation, even if they have different means (e.g., revenues versus gross margin) or different scales of measurement (e.g., yields in kg versus prices in euro).

Farm income volatility, and coefficient variation, differs substantially between and within agricultural sectors. In the current study, we report median (the 50 percentile value) CVs to estimate the central tendency. In the study of Vrolijk et al. (2009), Tukey M-estimators were used whereby weighting the observations were based on their deviation from the mean, but these are intuitively more difficult to comprehend. Mediums and $\mathrm{M}$-estimators both have the advantage that they are less sensitive to outliers or extreme values in the data set than average values. Note that CVs are not an ideal index since when the mean value is close to zero, the CV will approach infinity and is therefore sensitive in these cases to small changes in the mean (arbitrarily the maximum level is set at $250 \%$ ).

The distribution is presented by means of the P20 (the 20 percentile value) and P80 (the 80 percentile value). In any given year, $60 \%$ of the businesses record a farm income which lies within the P20-P80 range, whilst $20 \%$ record a household income greater than the $\mathrm{P} 80$ level and a further $20 \%$ record a household income lower than the P20 level.

\subsection{Resilience}

Resilience is generally considered as the capacity of a complex system to adapt to changes and continue to function and develop (Holling, 1973) and is interpreted in the current study as financial robustness to cope with the occurrence of adverse external events. First, for every farm in the panel the normal uncertainty observed in the past was calculated. Second, based on the financial structure of the farm, an analysis was based on how robust a farm would be after an external event that would reduce the output value. Downside risk will be specified as the percentage of farms that will suffer from a worsening continuity perspective (or possible bankruptcy) due to a price or revenue decrease as a consequence of a possible crisis (i.e., 30\% reduction). Note that FADN, being a bookkeeping system, does not capture indicators of whether certain special events occurred. To analyse the impact of external events on the farm performance it is therefore necessary to either deduce from the data that something special occurred or by using other information or knowledge on the occurrence and scope of external events.

To establish the financial robustness of a farm, farms were - in line with Vrolijk et al. (2008) categorised into four categories:

- Category 1

Family farm income is (still) positive (after the external event);

- Category 2

Family farm is negative, but postponing redemption (assumption: redemption equals depreciation) is an option thereby creating a positive family farm income;

- Category 3

Family farm income cannot be compensated with postponing redemption. Unless the farmer has liquidities to compensate for the negative income, financial distress will be the result.

- Category 4

Family farm income is already negative before external shock; the external event only worsens the situation.

Note that family farm income as reported takes into account interest paid and depreciation. 


\subsection{Price contracts, diversification and off-farm income}

Several price contracts are available to farmers, such as:

1. pooling contract with or without a bottom price

2. fixed-price contract and

3. a price based on a benchmark (or a mix of these contracts in combination with partly selling on the spot market).

By means of a price pooling contract, the total gross returns of the sales, minus costs, is distributed among farmers in proportion to the amount delivered (differentiated with the delivery moment by means of average costs for storage facilities). The advantage of such cooperative structures, or services offered by private companies, is that sales are spread over time, thereby reducing price risks. Farmers can also opt for a specified bottom-price whereby payments of this bottom-price are made irrespective of worse market outcomes (as long as the intermediate party does not default). Another option consists of selling a net amount at a fixed contract price. The advantage of pooling contracts offered by cooperatives as well as by private companies is that price volatility is reduced since sales are spread over time, although some volatility remains. Dutch farmers that sell on the basis of a fixed price contract have cancelled out price volatility completely, at least for that portion for which a contract is issued but it is common to use a mixture of the alternative price and pooling contracts. Obviously by means of the described contracts the downside risk is restricted but this also holds for the upside potential.

FADN, being a bookkeeping system, does not contain indicators on adoption and impact of price contracts. Note that impact assessment is complicated by the fact that bookkeeping data are a summation of all effects over a period of time (e.g., joint business decisions and external effects). In the current analysis, we use price contract information which was recorded in the Innovation Monitor (2009-2012) and includes the following characteristics (for a maximum of four contracts in each year per farm):

- Contracted activities (i.e., crop or livestock species or product)

- Type of contract (i.e., no price contract, minimum price, pool, benchmark, fixed price)

- Contracted amount (i.e., total produced or fixed amount)

- Contracted turnover (i.e., <20\%, [20\%-50\%>, [50\%, 100\%>, 100\%)

- Delivery date (i.e., fixed delivery date or flexible delivery date)

- Contract quality (i.e., quality standards or no quality standards).

It is specified in the Innovation Monitor that contracts only focusing on delivery specifications, and thus price arrangements, are not part of the contract, and have consequently been excluded from the survey (e.g., standardised milk contracts, sugar beet contracts, manure contracts and energy contracts).

For the purpose of this study, that is to analyse income volatility and off-farm coping strategies, the broadest definition of farm households and their income sources has been retained. Total household income includes all earned income both from farming and non-farming activities, property income from investments, and social transfers from pension, health, unemployment schemes and various social safety nets (OECD, 2003). The adoption (and impact) of off-farm income is measured as the relative income stream compared to family farm income per year. Finally, heterogeneity of level of diversification is measured as the relative importance of the revenue stemming from the main activity compared to the total farm revenue each year. 


\section{Income volatility and resilience}

\subsection{Volatility and resilience in the arable crops sector}

In arable crop farming large fluctuations in family farm incomes are observed between years (Figure 3.1). This was also observed in the study of Vrolijk et al. (2009), which analysed the period 1990-2003. Highest average farm incomes were realised in 2006, 2010 and 2012, although also heterogeneity between farms was highest in these years (i.e., largest P20-P80 range). In relative lean years (2002, 2004 and 2011), approximately $20 \%$ of the arable farmers realised negative household incomes.

Ranking the best performing and worst performing farms in year $t$ and comparing that with results in year $\mathrm{t}-1$ reveals that ranks are relatively stable. For example $68 \%$ of the arable farms which are categorised in the higher quintile $t$ (representing $20 \%$ of the population), were already in the highest two quintiles in year t-1 (representing $40 \%$ of the population). Moreover, the probability of relative adverse incomes based on outcomes of previous years were even more profound; $86 \%$ of the arable farms which are categorised in the lowest quintile $t$, were already in the lowest two quintiles in year $\mathrm{t}-1$.

The standard deviation between years within a farm was often less than the mean farm income. The average annual farm income was approximately 100,000 euros, and the standard deviation 132,000 euros. Across all farms, hence, a median CV level of $75 \%(100,000 / 132,000 * 100)$ was measured (Figure 3.1). Also with this standardised measure for volatility, substantial heterogeneity was observed between arable farms.

More in-depth analysis by splitting the sample in two equivalent portions to compare farms with relative low versus high volatility revealed that association with farm size (measured in SO) was not significant (T-test). Association between volatility and adopted risk management strategies is described in the following chapter.

Note that, based on similar FADN data, Berentsen et al. (2016) found that the risk at the level of family farm income is significantly higher in organic arable farming than in conventional arable farming. The underlying variables show higher risk for organic farms in overall labour cost, crop prices and variable input costs per crop.

Dutch arable crop farming is well diversified and cultivates a wide range of crops such as wheat, barley, seed potato, starch potato, ware potato, sugar beet and seed onion. Income volatility is mainly caused by large deviations in gross margin levels for ware potatoes between years (a crop not regulated by the CAP and with a strong business cycle), and to a lesser extent by other crops, e.g., (seed) onions which is on average tilled on a relative small proportion of the total land available. Volatility in gross margins is caused by joint volatility in variable input costs, crop yields and output prices (Figure 3.2). Note that CV values of gross margins often exceed the CV values of underlying components since mean values are relatively low (variable costs are subtracted from the revenue) and underlying revenue components (i.e., yield and price) are limited correlated (and thus reduction in overall variance is limited). 

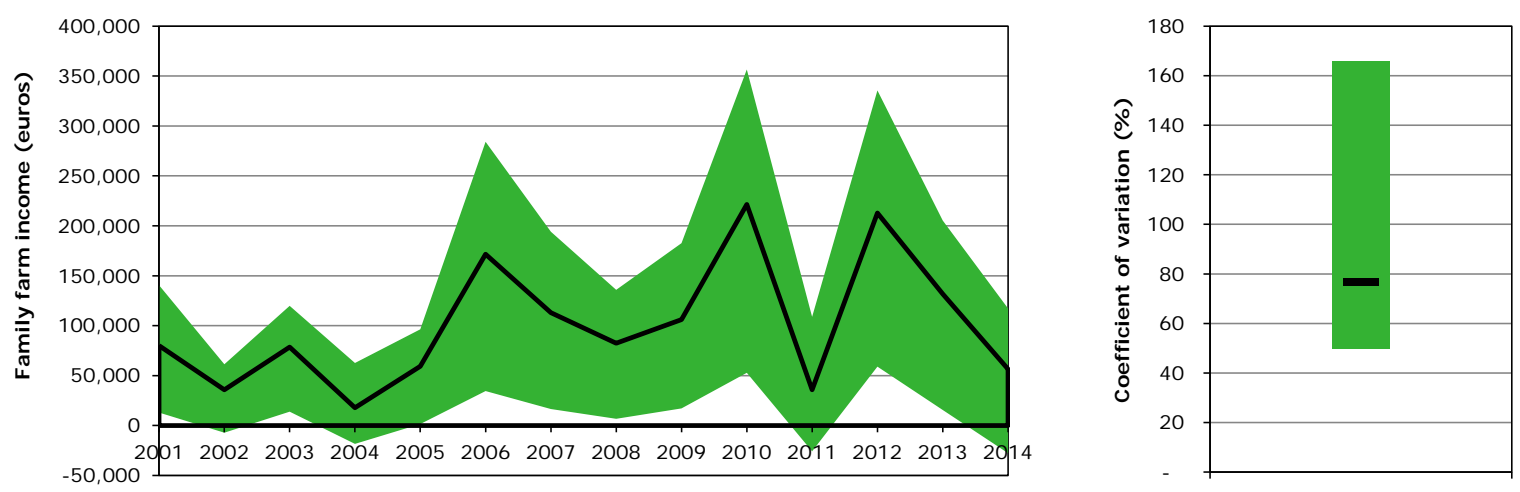

Figure 3.1 Volatility of family farm income and coefficient of variation on arable farms (median, P20 and P50).

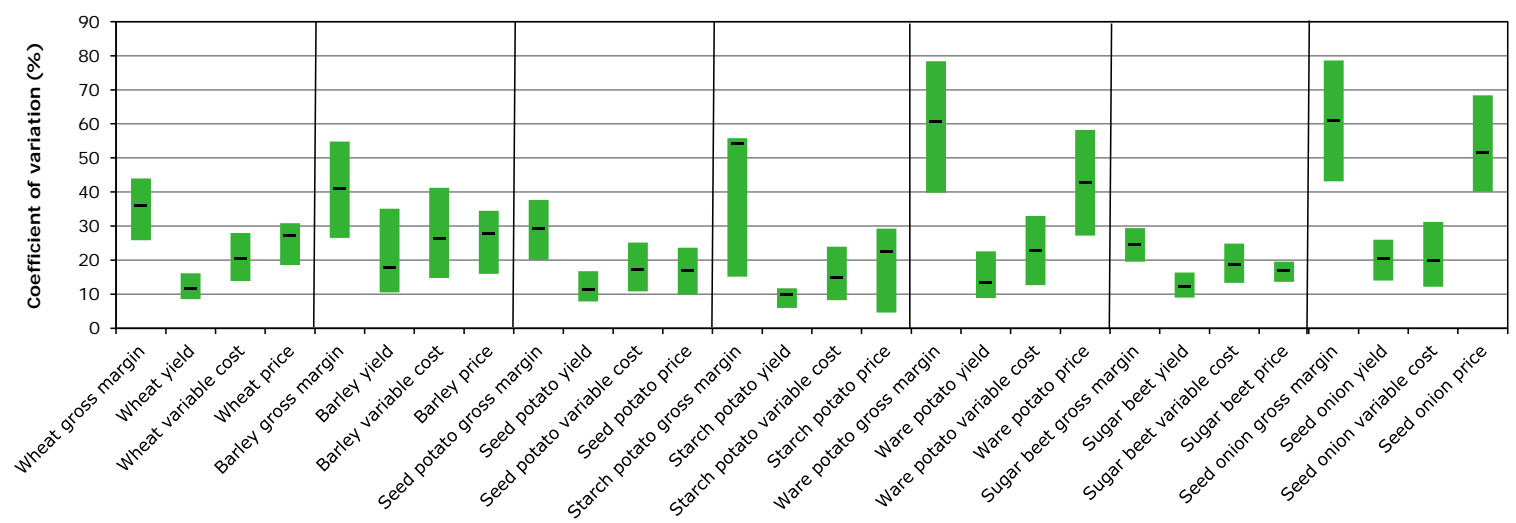

Figure 3.2 Coefficient of variation per cropping activity on arable farms (median, P20 and P50).

There are distinct differences in the financial robustness of arable farms as displayed in Figure 3.3 to assess the business' ability to settle all its expenditure (positive net cash flow). The volatility of financial robustness over time is strongly affected by the farm incomes in previous years. The average proportion of arable farms with a positive cash flow after depreciation amounts to approximately $90 \%$. The average proportion of farms with negative cash flows, if depreciation is not accounted for, is relatively constant over time and amounts to $4 \%$. Even after an external shock of a $30 \%$ decline of total revenues, the majority of arable farms still maintain a positive income, although $20 \%$ of the arable farms are at risk.

Whether financial distress leads to major adjustments to absorb the deficit (which can ultimately cause bankruptcy) depends on many other factors such as business' liquid assets to absorb negative cash flows, deferring repayments, farm wealth, off-farm wealth and off-farm income.

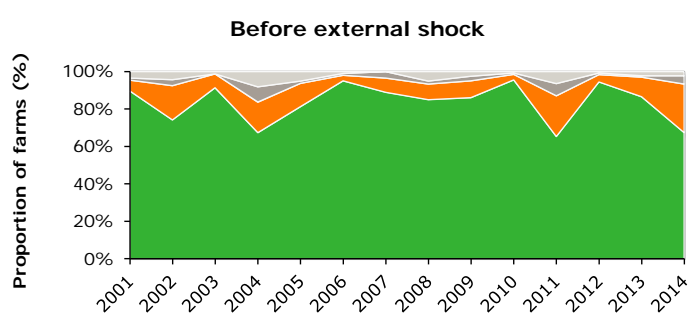

Negative farm income without redepreciation and negative cash flow = Positive farm income without redepreciation and negative cash flow Positive income without depreciation

- Positive farm income

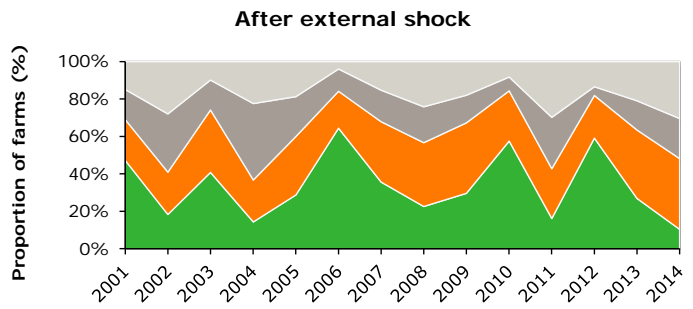

$=$ Negative farm income without redepreciation and negative cash flow = Positive farm income without redepreciation and negative cash flow - Positive income without depreciation

- Positive farm income

Figure 3.3 Resilience before and after external shock on arable farms. 


\subsection{Volatility and resilience in the horticulture sector}

Average farm incomes in horticultural subsectors are subject to significant fluctuations. In the volatility analysis, a distinction is made between three subsectors in horticulture, namely producers of vegetables, cut flowers and potted plants (and bedding plants). Figure 3.4 provides an overview of the development of the farm incomes in horticulture, as well as an indication of the volatility of farm incomes. Sharp falls alternate with years in which farm incomes rise substantially. For example, high (i.e., 2014) or low (i.e., 2008 and 2009) average household incomes resulted from favourable or unfavourable developments in the prices of horticultural products.

Ranking the best performing and worst performing farms in year $\mathrm{t}$ and comparing that with year $\mathrm{t}-1$ reveals that ranks are relative stable. For example $66 \%$ of the horticultural farms which are categorised in the higher quintile $t$ (representing $20 \%$ of the population), were already in the highest two quintiles in year t-1 (representing $40 \%$ of the population). Moreover, $73 \%$ of the horticultural farms which are categorised in the lowest quintile $t$, were already in the lowest two quintiles in year $\mathrm{t}-1$. More in-depth analyses revealed that the probability of being trapped is more profound in the subsector producing potted plants.

The standard deviation between years within a holding exceeds the average farm income, and hence the median CV amounts to $139 \%$. The median and range of CV values is higher and wider in the subsectors vegetable and cut flower production than in the subsector of potted plants. Volatility of more specific crop gross margins and variable costs are depicted in Figure 3.5. Splitting the sample in two equivalent portions revealed that in each subsector farms with a relative high income volatility were significantly larger (T-test and size measured in SO). As expected, specialisation and expansion both enable to exploit efficiency of scale, but thereby become more exposed than small diversified holdings. Association between volatility and adopted risk management strategies is described in the following chapter.
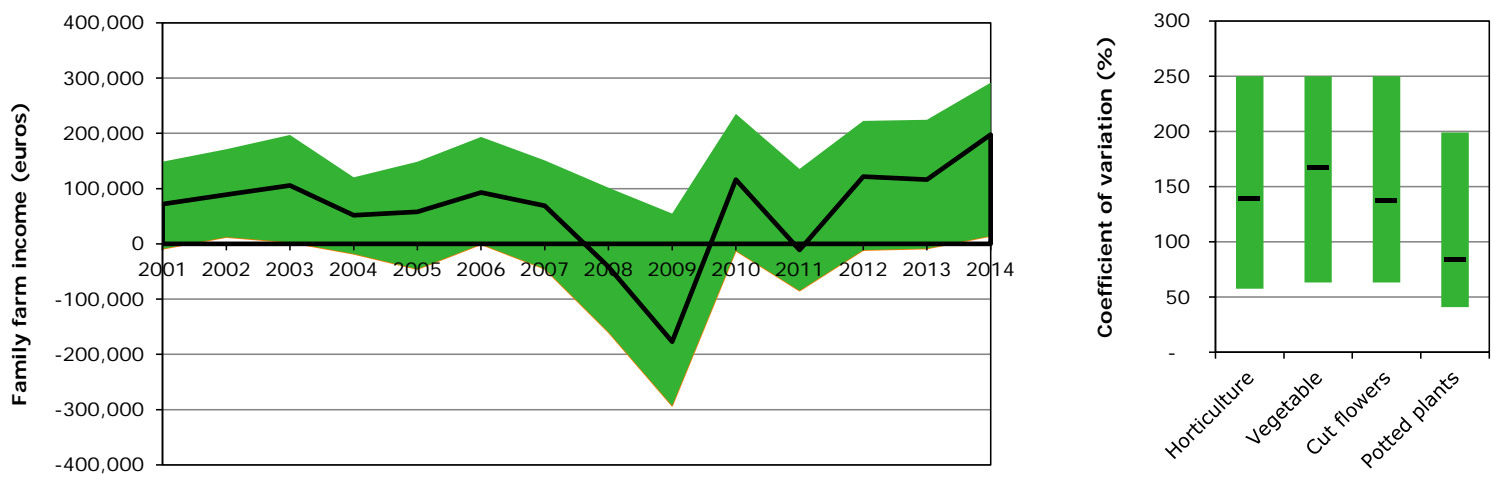

Figure 3.4 Volatility of family farm income and coefficient of variation on horticultural farms (median, P20 and P50).

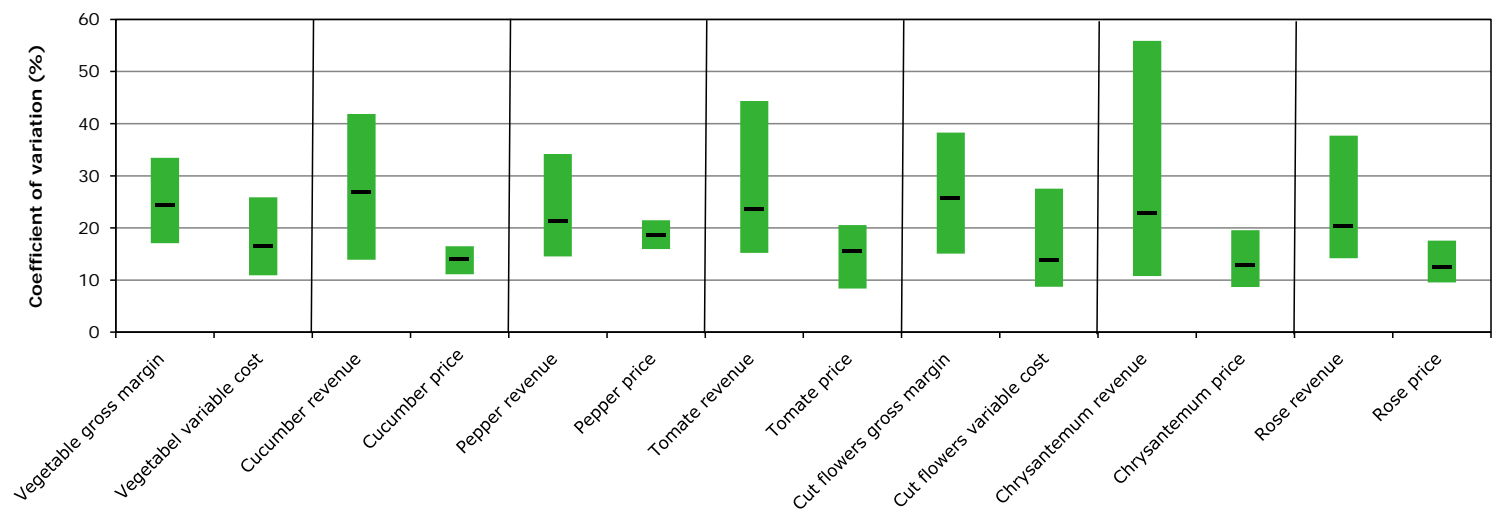

Figure 3.5 Coefficient of variation per cropping activity on horticultural farms (median, P20 and P50). 
To categorise the financial robustness the same approach as is used in the previous section on arable farms is used for horticulture farms. The percentage of farms with a positive income before as well as after a hypothetical shock is much lower than in the arable sector. Moreover, this sector has in comparison a relatively low level of solvability and a high level of farm income volatility. There are clear differences in the financial robustness between horticulture farms (Figure 3.6).
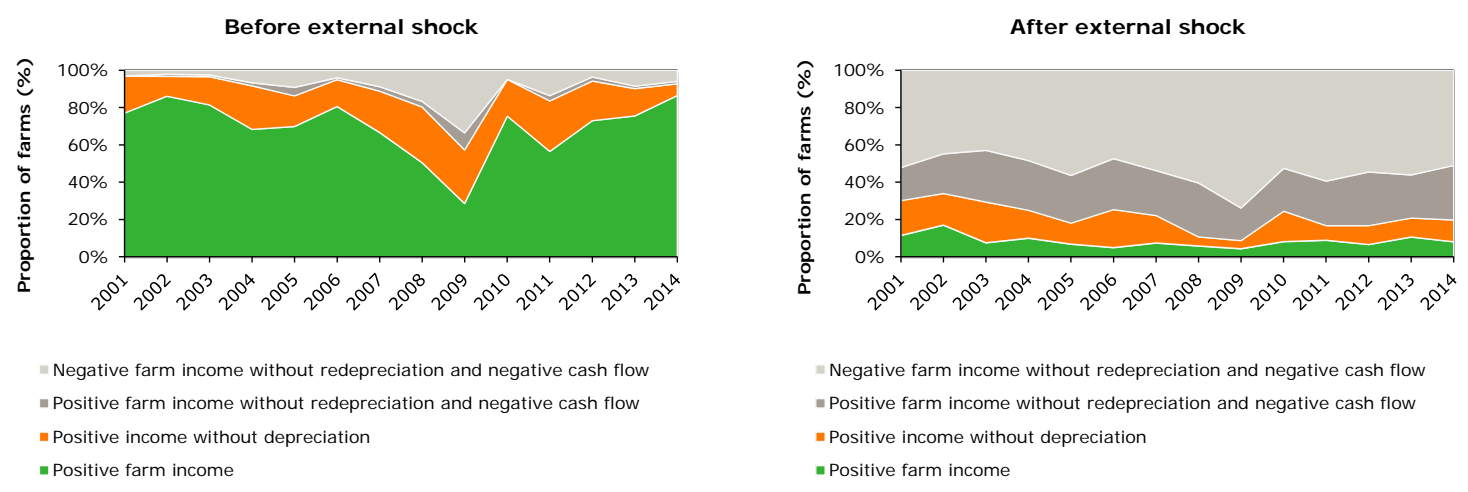

Figure 3.6 Resilience before and after external shock on horticultural farms.

The volatility of the financial robustness over time is strongly affected by farm incomes in previous years. The average proportion of farms with negative cash flows, if depreciation is not accounted for, is volatile, and amounted to approximately one-third during the aftermath of the crisis in 2009. In 2014 , this category of farms at risk dropped to a proportion of $6 \%$. The improved cash flows have reduced the number of bankruptcies. Up to November 2015 the number of bankruptcies in the vegetable sub-sector comprised 16 in comparison to 24 in 2014 and 60 in 2013 . Corresponding numbers for the cut flower subsector were 19 in 2015, 3 in 2014 and 30 in 2012 (www.agrimatie. nl). Despite recent increased cash flows, more than $50 \%$ will fall in the category of farms at risk if an extreme external shock will occur again.

\subsection{Volatility and resilience in the dairy sector}

Dairy farms in the lowest quintile of incomes in a certain year remain often in the lower quintile in the next year and can relatively seldom improve their (relative) income position by moving to another quintile. In fact off all sectors analysed the probability of being trapped in one of the income quintiles is most profound in the dairy sector. Ranking the best performing and worst performing farms in year $\mathrm{t}$ and comparing that with farm incomes from year $\mathrm{t}-1$ reveals that ranks are relative stable. For example $86 \%$ of the dairy farms which are categorised in the higher quintile t (representing $20 \%$ of the population), were already in the highest two quintiles in year $\mathrm{t}-1$ (representing $40 \%$ of the population). Moreover, $92 \%$ of the dairy farms which are categorised in the lowest quintile $t$, were already in the lowest two quintiles in year $\mathrm{t}-1$.

Lowest average nominal household incomes were realised in 2009 as a result of unfavourable developments in the prices of milk prices and dairy products. Yet, farm incomes in the dairy sector are less volatile than in other sectors analysed, since the median CV amounts to $60 \%$. Also the heterogeneity between farms is less wide (Figure 3.7). Volatility was statistically (T-test) higher on smaller dairy farms (split sample in two equivalent portions to compare dairy farms with relative low versus high volatility). Association between volatility and adopted risk management strategies is described in the following chapter.

Until recently, nominal milk prices were more or less stable under the milk quota system, which was abolished on 1 April 2015. It is clear that milk prices and dairy products in the EU will become more volatile as a response to the transformation of the classical price support regime of the CAP into a safety net provision. As a result, prices for dairy products in the EU are increasingly related to world market prices, and are also affected by the volatility of these prices (J ongeneel and Van Berkum, 2015). 

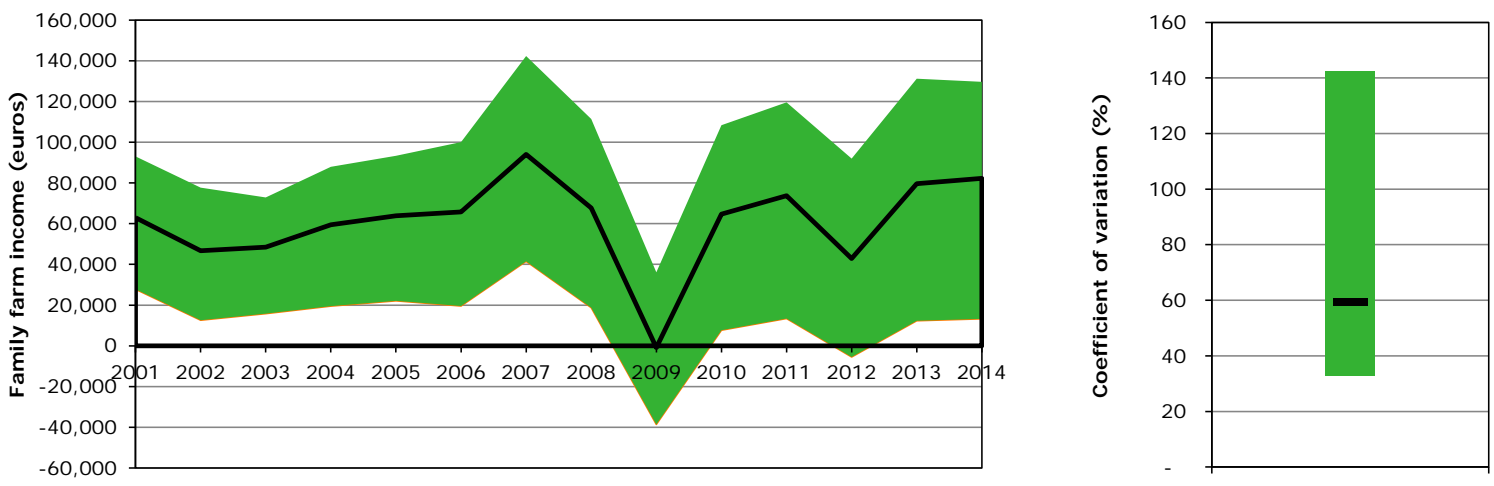

Figure 3.7 Volatility of family farm income and coefficient of variation on dairy farms (median, P20 and P50).

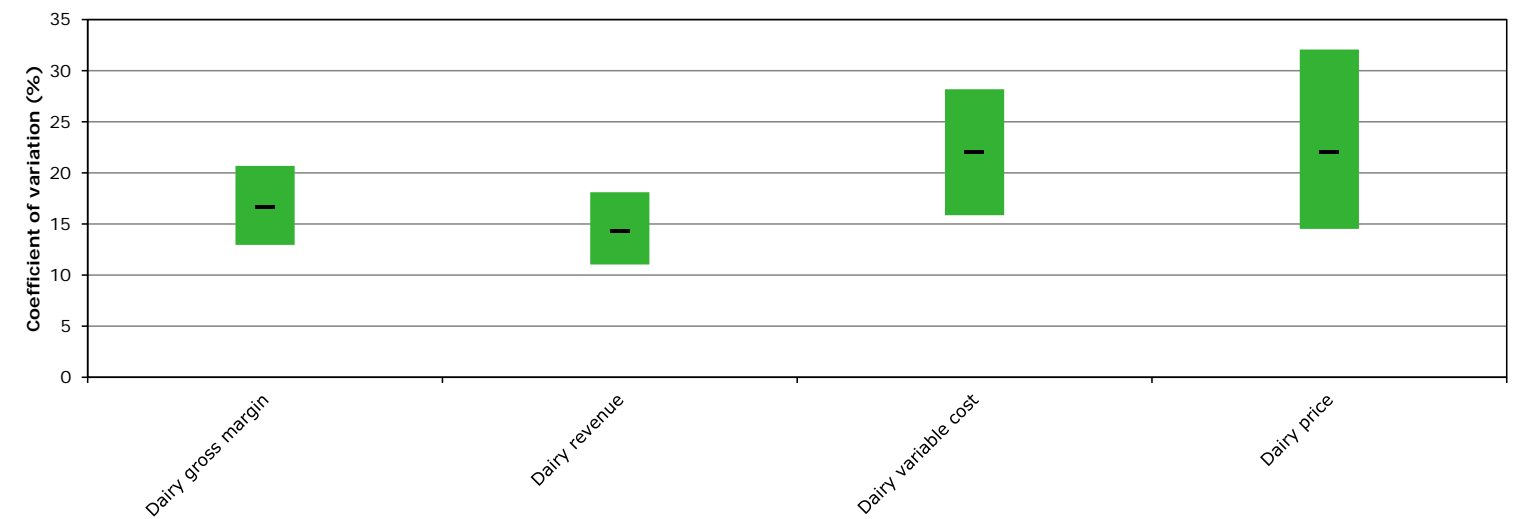

Figure 3.8 Coefficient of variation per activity on dairy farms (median, P20 and P50).

Two key factors determining family farm income are the farm-gate milk and feed prices. The factory price of milk and the feed concentrate price tend to move in a similar direction (Jongeneel and Van Berkum, 2015). Higher milk prices are offset by higher feed costs, and vice versa, and this positive correlation smoothens income. The cyclical fluctuations of supply and prices in livestock markets can be rationalised based on production lags and adaptive expectations. This phenomenon is captured by higher CV values for variable costs and dairy prices in comparison to gross margins (Figure 3.8).

Note that based on similar FADN data, Berentsen et al. (2012) found that the risk included in the gross margin per cow is significantly higher in organic dairy farming compared to conventional dairy farming. This is caused by both higher price and production risks. Price risks are significantly higher in organic farming for both milk price and concentrate price. With regard to production risk, only milk yield per cow poses a significantly higher risk in organic farming.

Financial robustness of dairy farms is relatively homogeneous across farms over time (Figure 3.9). Compared to other types of farming, the differences between dairy farmers are very limited and relatively stable. As a result of low average farm incomes in 2009 , the category of dairy farms with negative cash flows increased (category 4) from an average of $1 \%$ up to $6 \%$. The number of dairy farms with a positive income after an hypothetical external shock without taking additional measures (category 1 ) in recent years was approximately $15 \%$. 

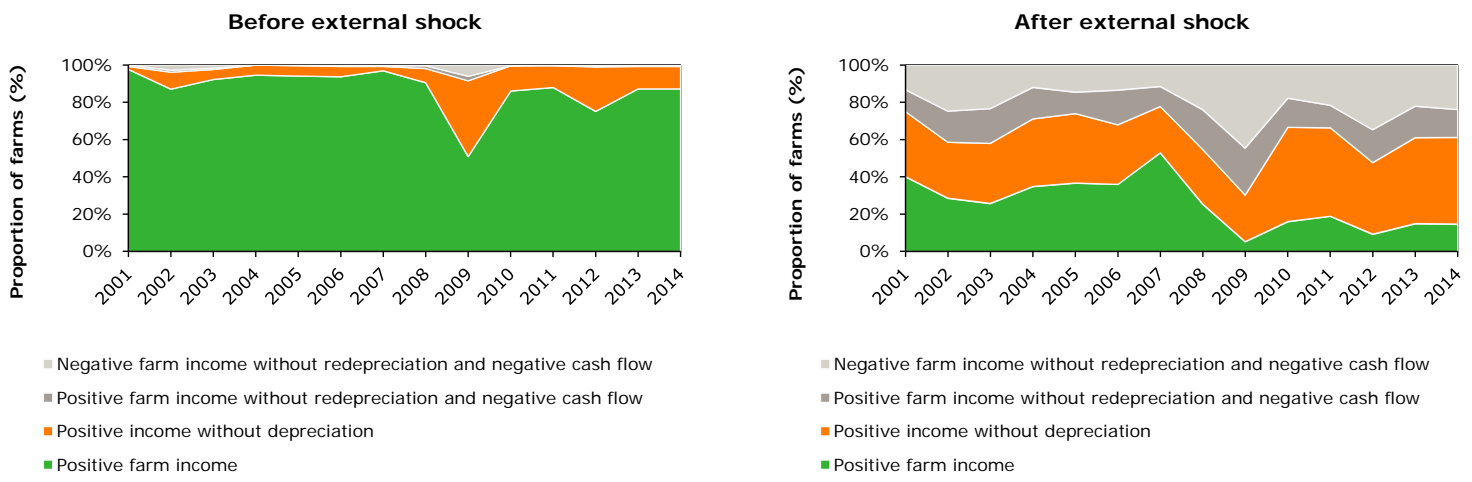

Figure 3.9 Resilience before and after external shock on dairy farms.

\subsection{Volatility and resilience in the pig farming sector}

Figure 3.10 provides an overall indication of the development of farm incomes on specialised pig farms (e.g., sow farms, fattening pig farms and farrow to finish farms) which is a sector with large fluctuations caused by, among others, the pig cycle phenomenon. Also, CAP has fewer direct effects to smoothen or enhance income in this sector. Moreover, net exporting countries such as the Netherlands suffer severely in weak markets (Vrolijk et al., 2009), although most pig farms are affected by the European market.

The pig farming sector suffered from economic recession which started in 2007-2008. The downturn in economic activity and higher input costs of animal feed, in combination with only small increases in market prices for their products have put additional extra pressure on farmers' incomes. More recently, pig farm incomes decreased in 2014 again primarily as a result of higher feed costs. Feed costs account for $60 \%$ of total paid costs and depreciation on pig farms (www.agrimatie. $\mathrm{nl}$ ).

Ranking the best performing and worst performing farms in year $\mathrm{t}$ and comparing that with year $\mathrm{t}-1$ reveals that ranks are relatively stable. For example, $66 \%$ of the pig farms which are categorised in the higher quintile $t$ (representing $20 \%$ of the population), were already in the highest two quintiles in year t-1 (representing $40 \%$ of the population). Moreover, $76 \%$ of the pig farms which are categorised in the lowest quintile $t$, were already in the lowest two quintiles in year $\mathrm{t}-1$. More in-depth analyses per subsector revealed that the probability of being trapped is more or less similar.

The median income fluctuation in terms of CV amounts 193\% (within farms between years), and does not differ much substantially between subsectors. Yet, there is also a high variation in economic performance between pig farms (Dolman et al., 2012), as indicated with the wide range of CVs (i.e., all subsectors have large P20-P80 ranges). More in-depth analysis by splitting the sample in two equivalent portions to make a comparison between sow farms or fattening pig farms with relatively low versus high volatility, revealed that association with farm size (measured in SO) was not significant (T-test). Association between volatility and adopted risk management strategies is described in the following chapter.

Figure 3.11 presents the coefficient of variation of gross margin, revenue, variable costs and output prices. Comparison of Figure 3.10 and Figure 3.11 reveals that the volatilities at farm level in terms of farm income (including fixed costs) are much higher than at underlying components (in terms of prices and variable costs). 

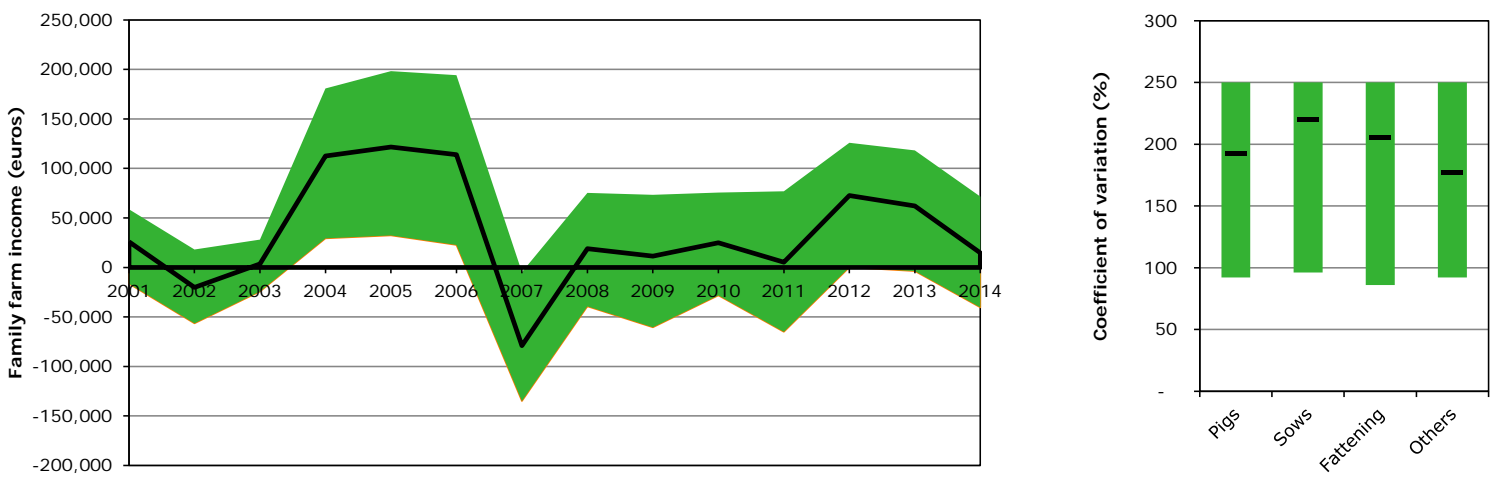

Figure 3.10 Volatility of family farm income and coefficient of variation on pig farms (median, P20 and P50).

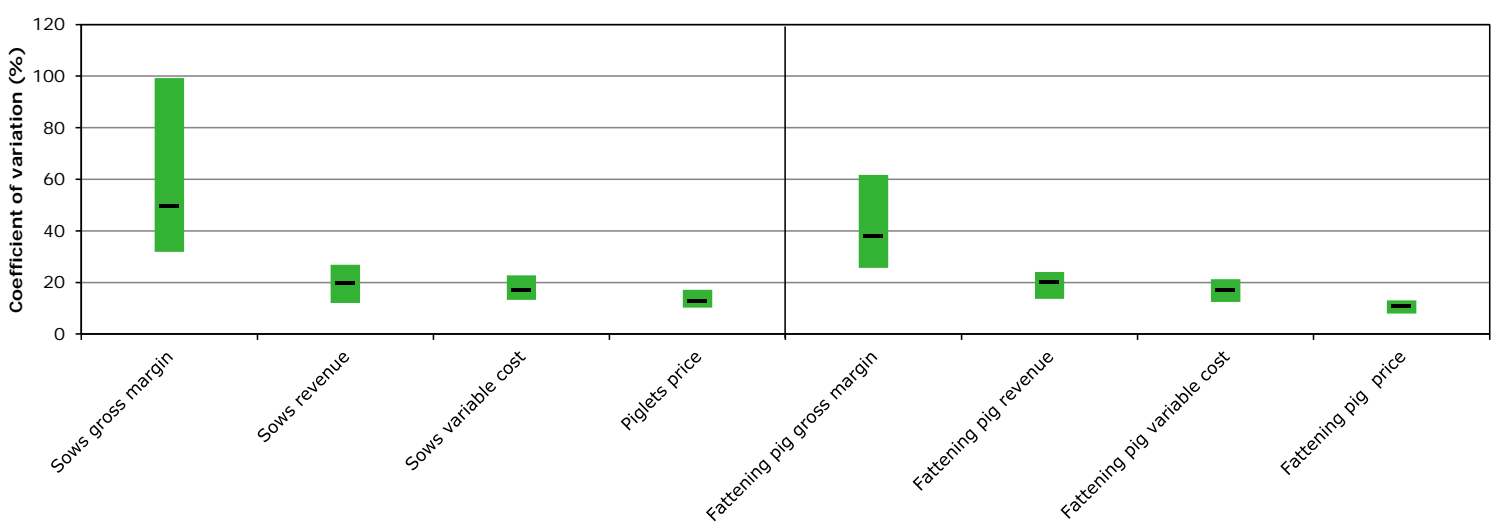

Figure 3.11 Coefficient of variation per activity on pig farms (median, P20 and P50).

Given the high volatility of farm incomes in the pig farming sector, and in intensive livestock sector in general, it is of interest to analyse their robustness (Figure 3.12). Compared to other types of farming the category of farms with positive cash flows is relative low in the aftermath of the recent recession. The number of pig farms with a positive cash flow (category 1 ) after an external shock is only $2 \%$ and thus the majority would end up in financial distress due to an external crisis. A large proportion of farms have a negative cash flow even without a simulated shock; more than one-third of the farms have negative cash flows (i.e., category 2, 3 and 4) in the period 2001 up to 2014. In general, sow farms are more represented in category 4 than fattening pig farms, requiring more substantial adjustments to absorb the deficit (www.agrimatie.nl).
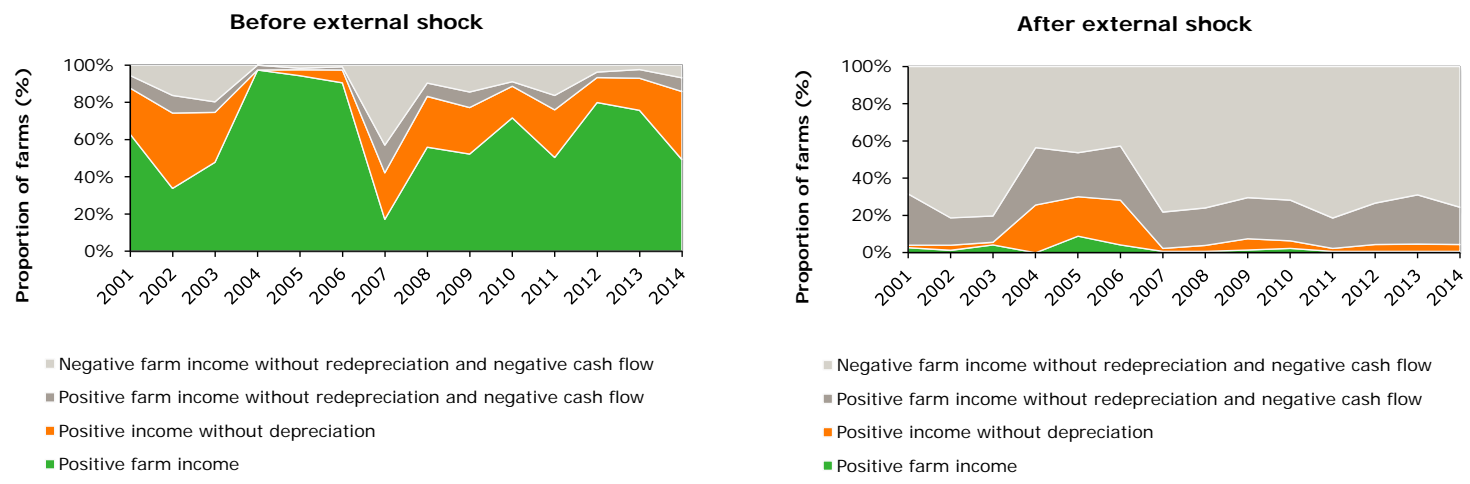

Figure 3.12 Resilience before and after external shock on pig farms. 


\subsection{Volatility and resilience in the poultry farming sector}

The poultry sector as well as the pig sector are both confronted with the largest fluctuations in household incomes of all sectors analysed. The median income fluctuation in terms of CV amounts $189 \%$ (within farms between years), with even more extreme fluctuation in the laying hen subsector than in the broiler subsector (Figure 3.13). Laying hen farm size was not associated with volatility. However, family farm income was more volatile on relatively small broiler farms (based on T-test and by splitting the sample in two equivalent portions to compare farms with relative low versus high volatility). Association between volatility and adopted risk management strategies is described in the following chapter.

Extremely negative household incomes were foundin several years (i.e., 2004, 2011 and 2013) due to low output prices and rising input feed costs. In the poultry sector, as well as in the pig sector, the impact of fluctuations in the prices of the main input (compound feed) is very strong (up to $75 \%$ ) (Vrolijk et al., 2009). Costs for feed account for 60 to $67 \%$ of total paid costs and depreciation (www.agrimatie.nl).

Poultry farms in the lowest quintile of incomes in a certain year can relatively often improve their (relative) income position by moving to another quintile. Of all sectors analysed, the probability of being trapped in one of the income quintiles is smallest in the poultry sector. Ranking the best performing and worst performing farms in year $\mathrm{t}$ and comparing that with results in year $\mathrm{t}-1$ reveals that ranks are relative instable. For example $48 \%$ of the poultry farms which are categorised in the higher quintile $t$ (representing $20 \%$ of the population), were in the highest two quintiles in year t- 1 (representing $40 \%$ of the population). Moreover, $56 \%$ of the poultry farms which are categorised in the lowest quintile t, were already in the lowest two quintiles in year t-1. More in-depth analyses per subsector revealed that the probability of being trapped is more or less similar. For example, $54 \%$ of the farms with laying hens and $50 \%$ of the broiler farms which are categorised in the higher quintile $t$, were already in the highest two quintiles in year t-1. Note that these probabilities per subsector are higher than at sector level since it takes into account difference between subsectors.
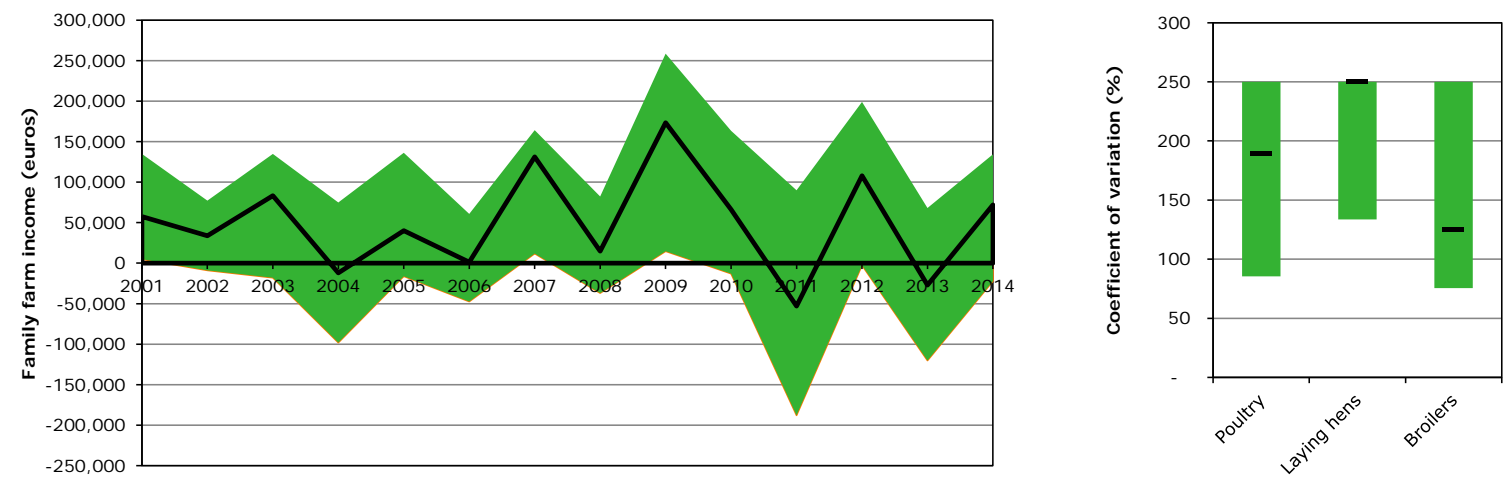

Figure 3.13 Volatility of family farm income and coefficient of variation on poultry farms (median, P20 and P50). 


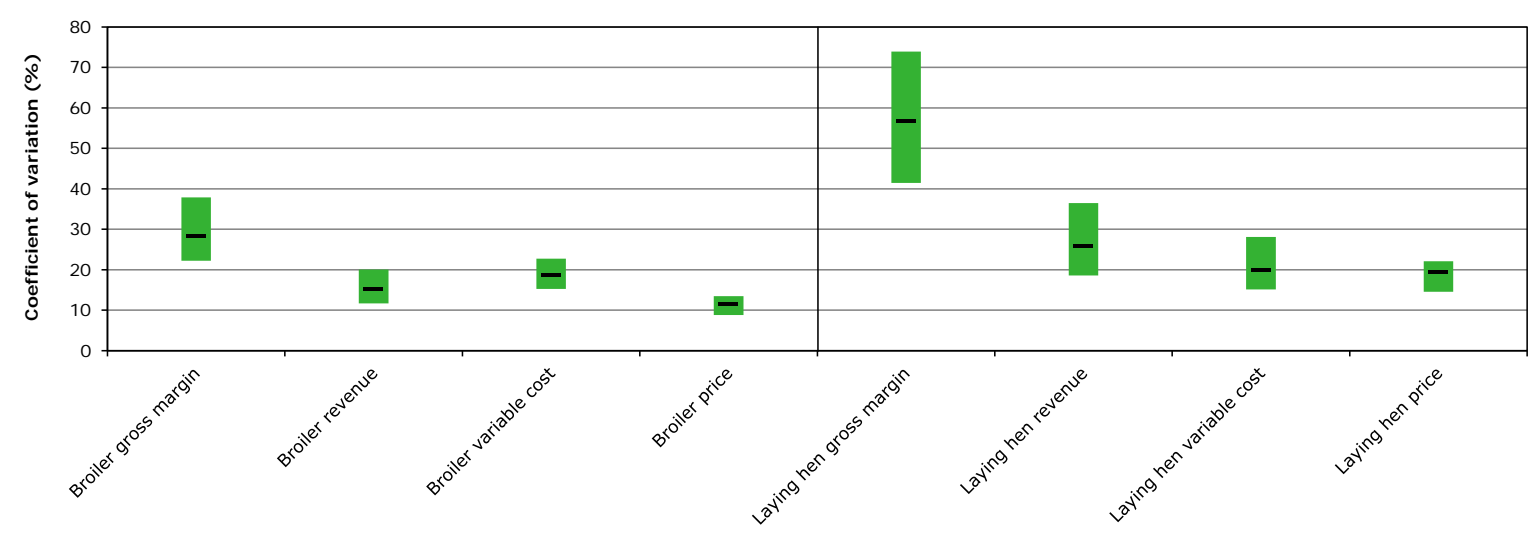

Figure 3.14 Coefficient of variation per activity on poultry farms (median, P20 and P50).

The category of farms with positive cash flows is relative low in the poultry sector, as well as the pig sector, compared to other types of farming (Figure 3.15). The number of poultry farms with a positive cash flow (category 1) after an external shock is only $6 \%$ and thus the majority would end up in financial distress due to an external crisis. Even a large proportion of farms have a negative cash flow even without a simulated shock; more than one-third of the farms have negative cash flows (i.e., category 2, 3 and 4) in the period 2001 up to 2014.

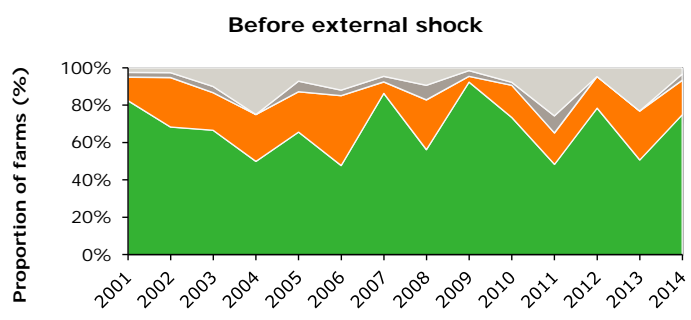

Negative farm income without redepreciation and negative cash flow - Positive farm income without redepreciation and negative cash flow = Positive income without depreciation - Positive farm income

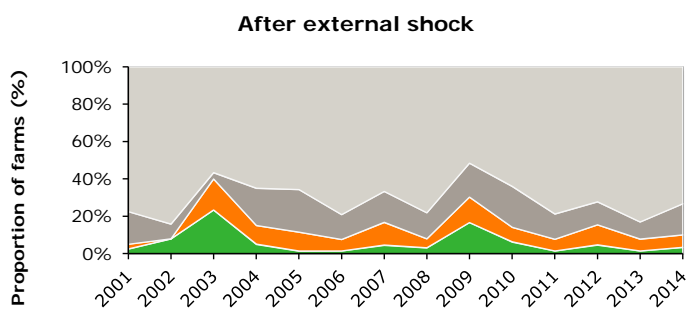

- Negative farm income without redepreciation and negative cash flow - Positive farm income without redepreciation and negative cash flow - Positive income without depreciation - Positive farm income

Figure 3.15 Resilience before and after external shock on poultry farms. 


\section{Adoption and impact of price contracts, diversification and off-farm income}

\subsection{Risk management strategies in the arable crops sector}

Price contracts are most frequently applied for potatoes on arable farms, and to a lesser extent for cereals and other arable crops. The use of price contracts is stable over time in the analysed period from 2009 through 2012 (Figure 4.1). Approximately 50\% have some kind of potato price contract of which the pool contracts and fixed-price contracts are the most common ones. The majority of producers who hedged potatoes, which is the main cash crop, contracted the majority of the acreage used for potatoes and its turnover. Those arable farms that adopted potato price contracts were on average significantly $25 \%$ larger (T-test and in terms of SO).

The level of potato price protection depends on the type of price contract and hedged amount, and the median potato price volatility was lower at farms with price contracts. The median CV values for ware potato prices were $19 \%$ on arable farms without a contract and $15 \%$ on farms with - any kind of price contract. Note that annual spot market price variation of ware potatoes in the analysed period with information on price contracts (2009-2012) was moderate, while in the period 2001-2014 the annual CV of ware potato prices was more volatile (CV 40\%). Moreover, in the period 2009-2012, no sharp price drop was observed, hence the impact of underwriting price contracts for the period analysed is limited. For all other crops the impact of price contracts could not be estimated robustly because of limited number of time-series observations.

Besides price also quality standards and delivering data are specified in the contract of which flexible delivery date is most common one.
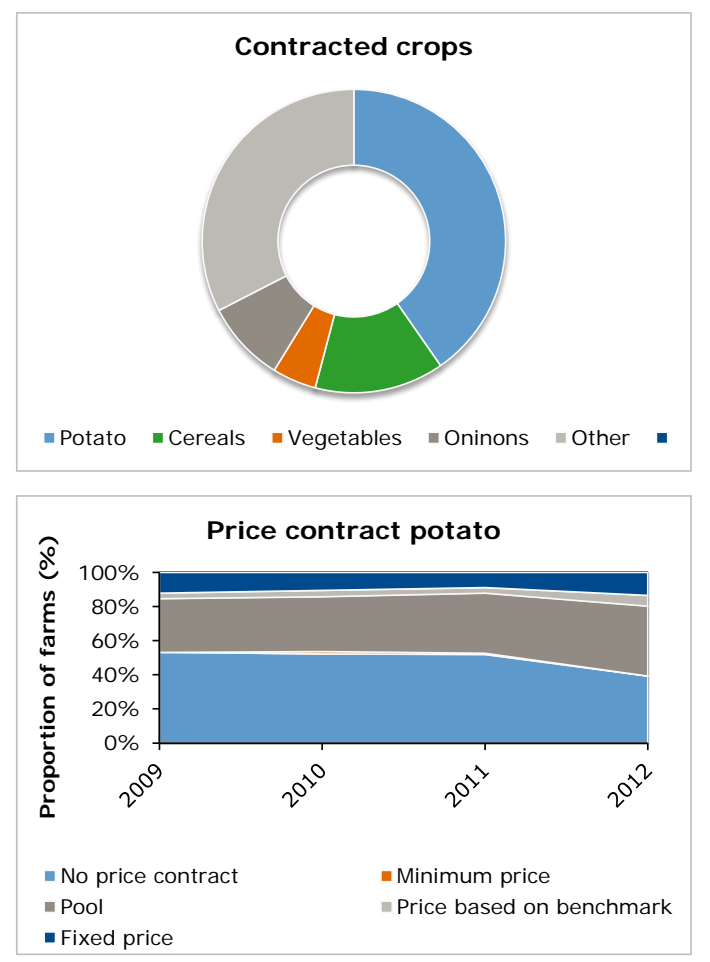
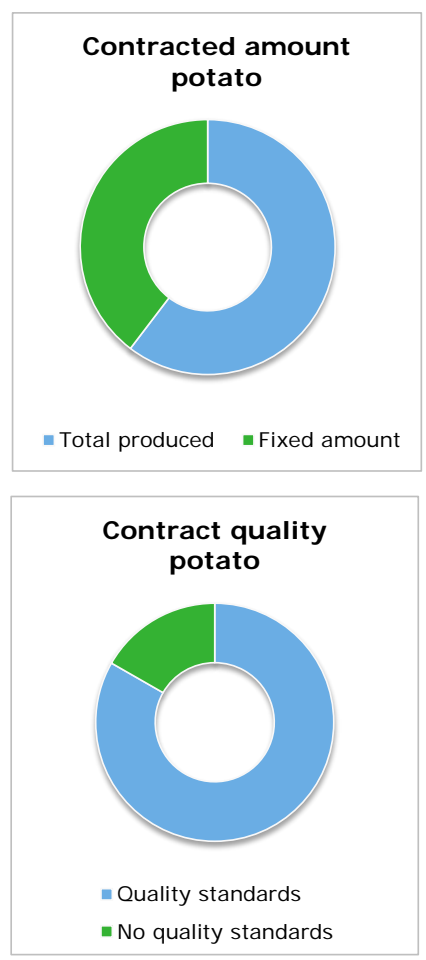

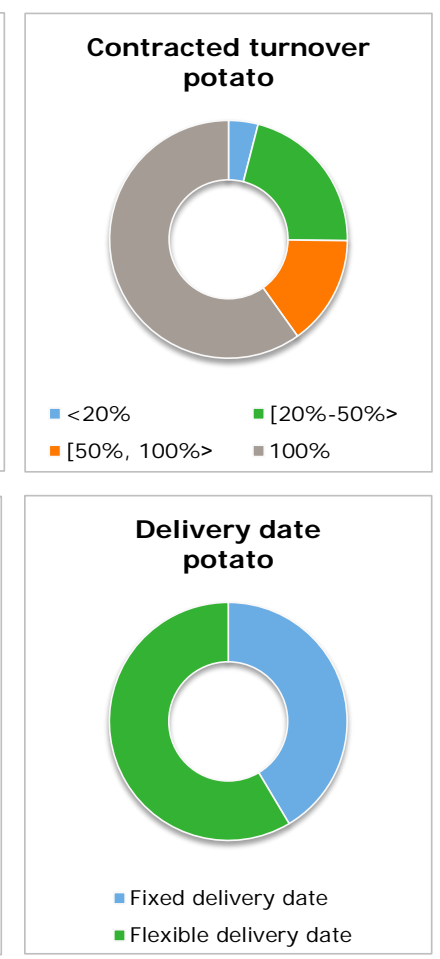

Figure 4.1 Adoption of price contracts on arable farms. 
On specialised arable farms the amount of off-farm income is limited (Figure 4.2A). Over the analysed time period, $95 \%$ of the household income stemmed from farming activies, and the remaining $5 \%$ originated from non-farming activities such as off-farm income, property income from investments, and social transfers from pension, health, unemployment schemes and various social safety nets. In adverse farming years, the proportion of (more stable) non-farming income increased, but remains in absolute values very limited, and thus provides for the majority of specialised arable farmers limited scope to cope with adverse farming years. Splitting the sample in two equivalent portions revealed that arable farms with a relative high off-farm income were significantly $37 \%$ smaller (T-test and size measured in SO).

The proportion of the revenue of the main activity compared to the overall farming revenue is used as a proxy for the level of diversification (Figure 4.2B). Over the analysed time period, approximately $50 \%$ of the farming income stemmed from the main cash crop (i.e., seed potato, starch potato, ware potato), and the remaining 50\% originated from several other cropping activities (e.g. wheat, barley, sugar beet and seed onion). The impact of diversification on arable farms as a risk management strategy is profound: Median CV values of revenue for ware potato is 35\%, whereas median CV value of farm revenue is approximately $25 \%$.

Of the analysed sectors, only arable farms widely apply diversification as a risk management tool (which is inherent because of agronomic constraints). Those arable farms that adopted more specialisation (above median level) were on average significantly $46 \%$ larger ( $\mathrm{T}$-test and in terms of SO). Note that only specialised farms were included in the analyses (mixed farms were excluded from the analysis).

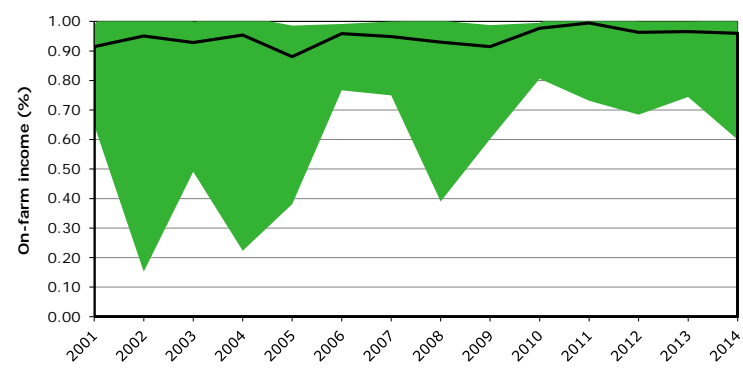

Figure 4.2A Adoption of non-farming income on arable farms (median, P20 and P50).

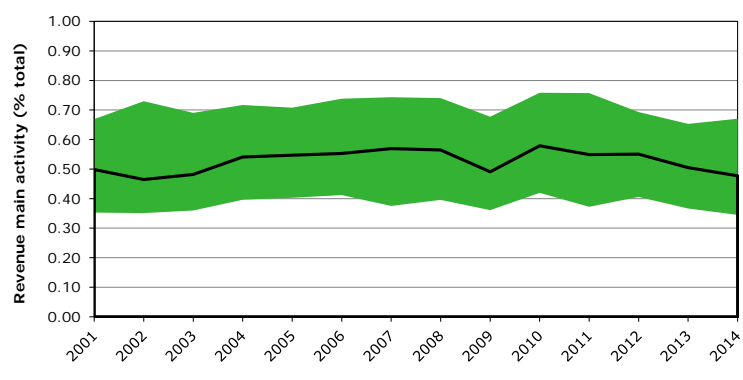

Figure 4.2B Adoption of diversification on arable farms (median, P20 and P50).

\subsection{Risk management strategies in the greenhouse horticulture sector}

The use of price contracts is stable over time in the greenhouse horticulture sector (Figure 4.3). The proportion of firms with a price contract is less than $10 \%$ and is more common in vegetable production than in potted plant and cut flower production. Vegetable producing greenhouse farms that do adopt price contracts were significantly $36 \%$ larger than non-adopting vegetable producers ( $T$-test and size measured in SO). Contract size with respect to acreage and turnover is heterogeneous. Besides price also quality standards and delivering data are specified in the contract of which a flexible delivery date is most common.

The level of price protection depends on the type of price contract and hedged amount. Since only a limited number of growers within each subsector have contracted their production or part of their production, the estimation of its impact on price volatility cannot be estimated robustly. 

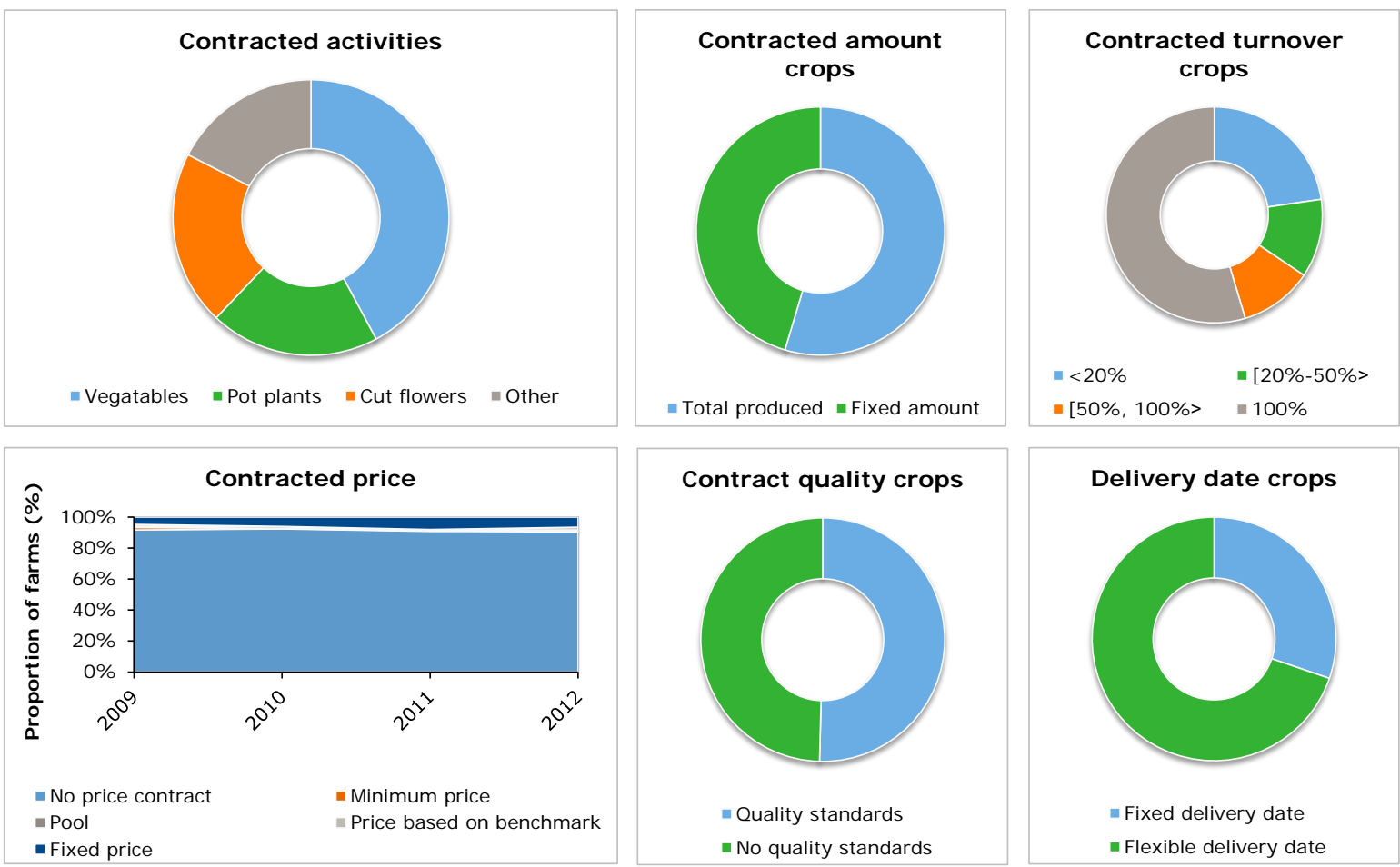

Figure 4.3 Adoption of price contracts on greenhouse horticultural farms.

On specialised horticultural farms the amount of non-farming income is limited (Figure 4.4). Over the analysed time period $95 \%$ of the family farm income stemmed from one main horticultural produce, and the remaining $5 \%$ originated from other farming activities. In summary, both non-farm income and on-farm diversification offer limited scope to smoothen income volatility on horticultural farms in the Netherlands.

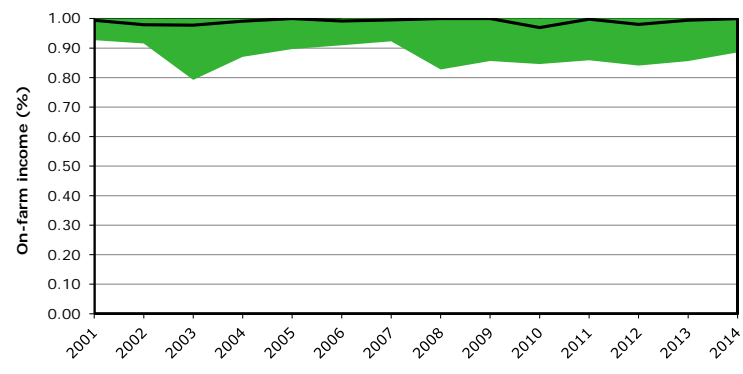

Figure 4.4A Adoption of non-farming income on greenhouse horticultural farms (median, P20 and P50).

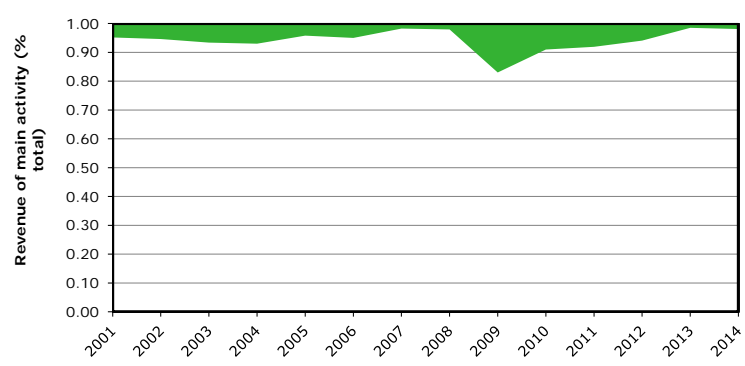

Figure 4.4B Adoption of diversification on greenhouse horticultural farms (median, P20 and P50).

\subsection{Risk management strategies in the dairy sector}

The adoption of milk price contracts is almost non-existing in dairy farming (Figure 4.5), while other cropping or livestock activities are sometimes contracted at diversified dairy farms (e.g., potatoes and cereals). With respect to price contracts, which are part of the Innovation Monitor, it was mentioned that milk contracts that focused specifically on delivery specifications only (which are widely adopted in the dairy sector) are excluded from the analysis. 
Also other analysed risk management strategies on dairy farms offer limited scope to smoothen income volatility since non-farm income and on-farm diversification are applied marginally. The median proportion of income stemming from non-farming amounts to $10 \%$ (Figure 4.6). Splitting the sample in two equivalent portions revealed that dairy farms with a relative high off-farm income were significantly $18 \%$ smaller (T-test and size measured in SO). On-farm diversification on specialised dairy farms was hardly applied (Figure 4.6).
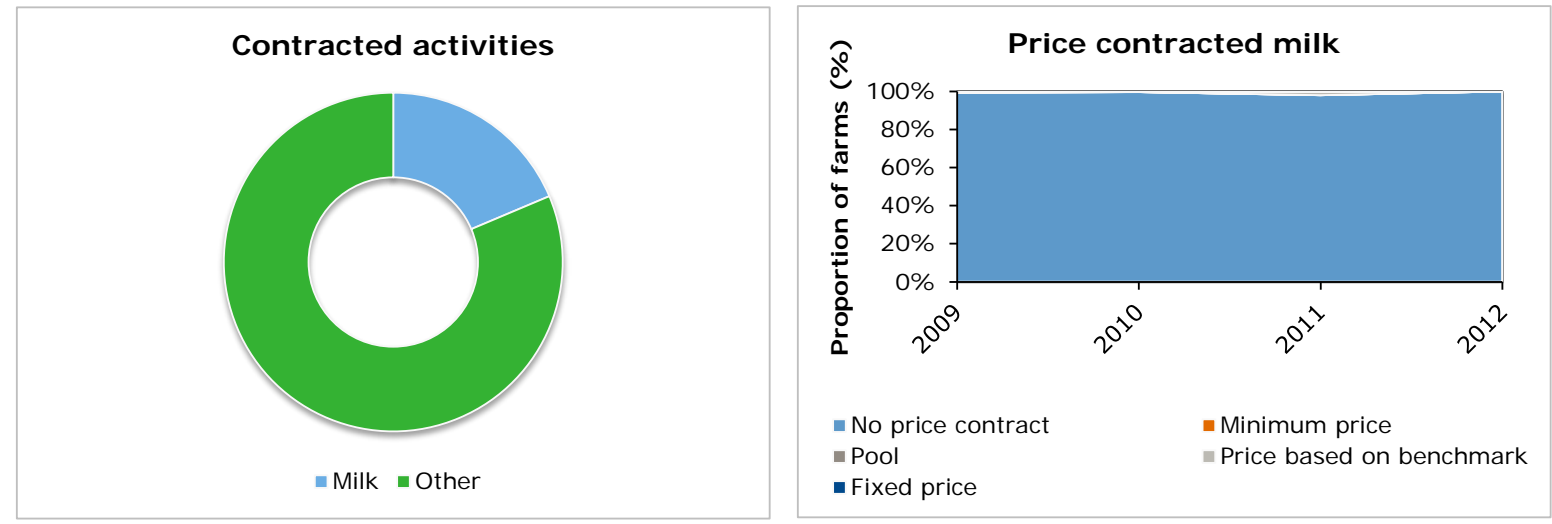

Figure 4.5 Adoption of price contracts on dairy farms.

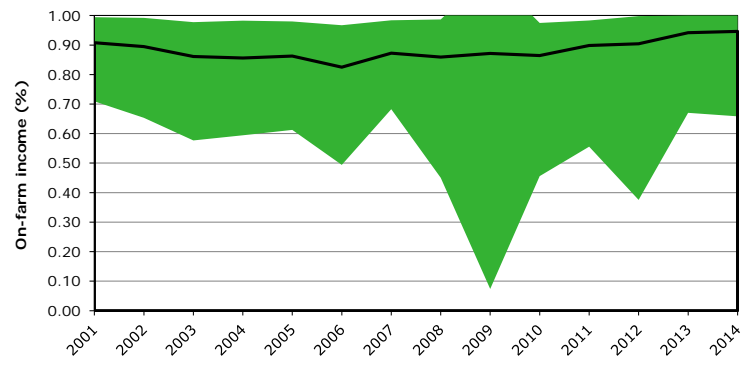

Figure 4.6A Adoption of non-farming income on dairy farms (median, P20 and P50).

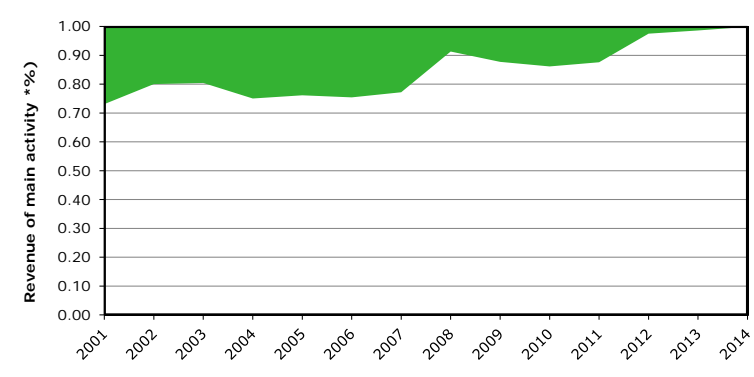

Figure 4.6B Adoption of diversification on dairy farms (median, P20 and P50).

\subsection{Risk management strategies in the pig sector}

The proportion of pig farms with a price contract, either to hedge meat price or piglet price, is less than 5\% (Figure 4.7). Contracts do generally entail the total annual turnover. Farm size was not significantly different between adopters and non-adopters of price contracts within the subsectors of sow farms and fattening pig farms (T-test and in terms of SO). Since only a limited number of pig farmers within each subsector have contracted their production or part of their production, the estimation of its impact on price volatility cannot be estimated robustly. 

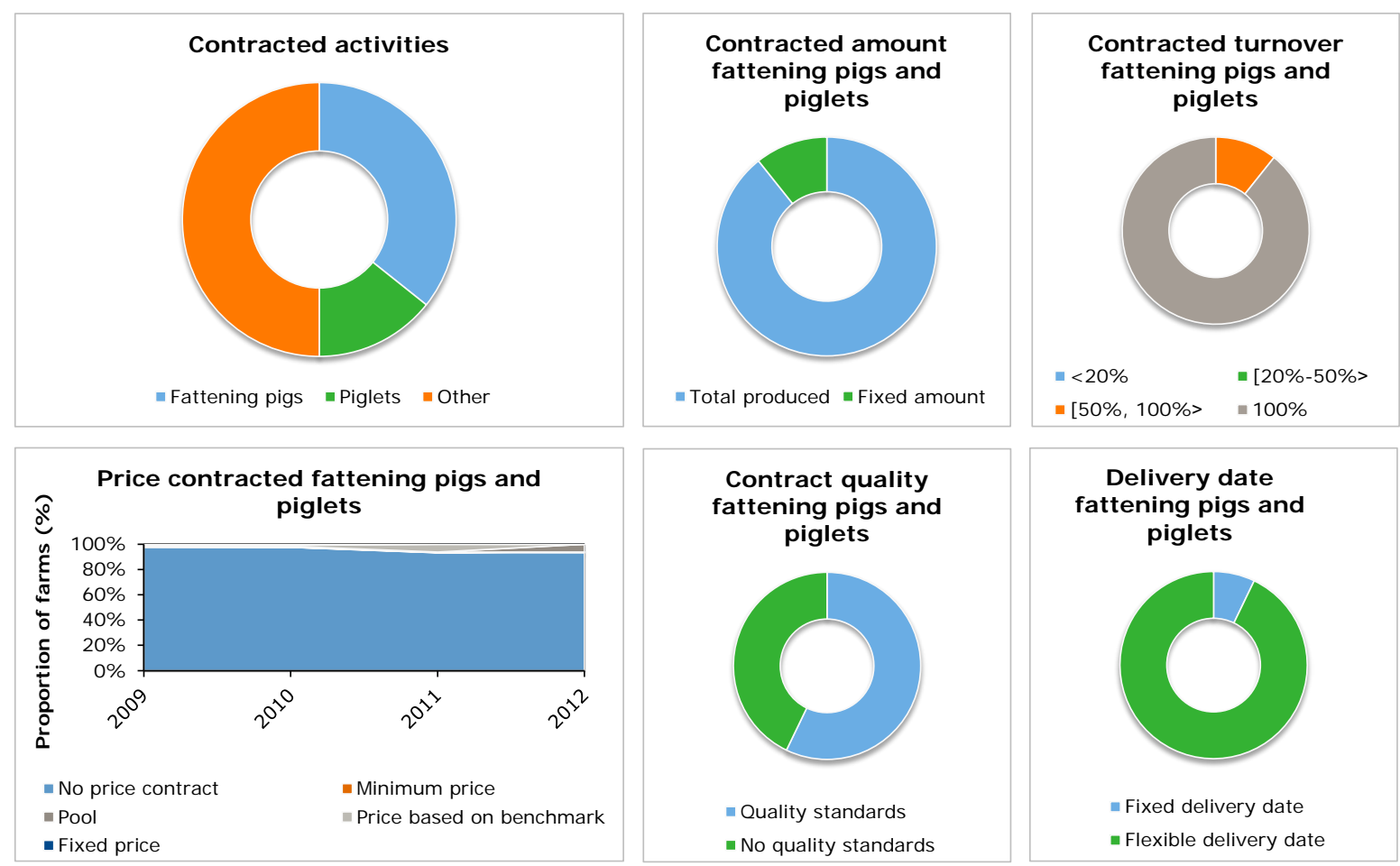

-Total produced $=$ Fixed amount
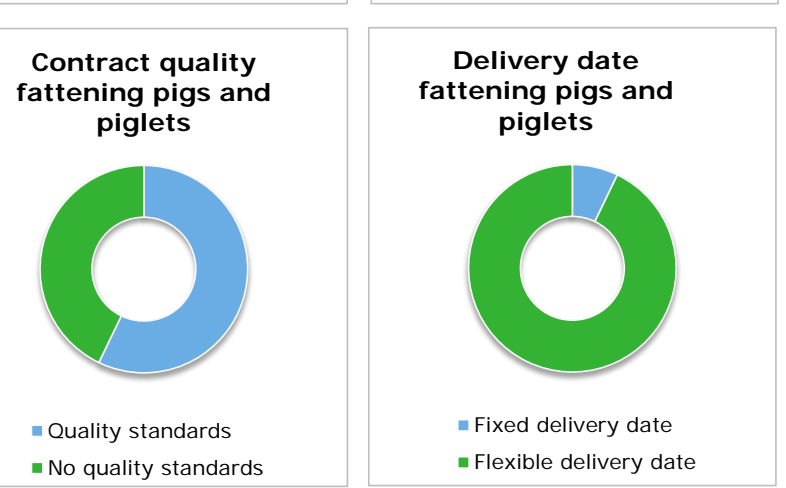

Figure 4.7 Adoption of price contracts on pig farms.

The median proportion of income stemming from non-farming income and the main on-farm income amount to $6 \%$ and $98 \%$ respectively (Figure 4.8 ). Pig farms with relatively more off-farm income were not significantly smaller ( $\mathrm{T}$-test and in terms of SO). Figure $4.8 \mathrm{~A}$ also reveals that the 20 percentile value (P20) is volatile between years, and P20 of total household income stemming from farming activities ranges from almost $0 \%$ up to $70 \%$ in the analysed period. This does not necessarily indicate that off-farm income is an effective diversification strategy to manage risks at household level, but stems more from low on-farm incomes in adverse farming years.

In summary, all analysed risk management strategies (i.e., price contracts, non-farm income and onfarm diversification) on pig farms offer limited scope to smoothen income volatility.

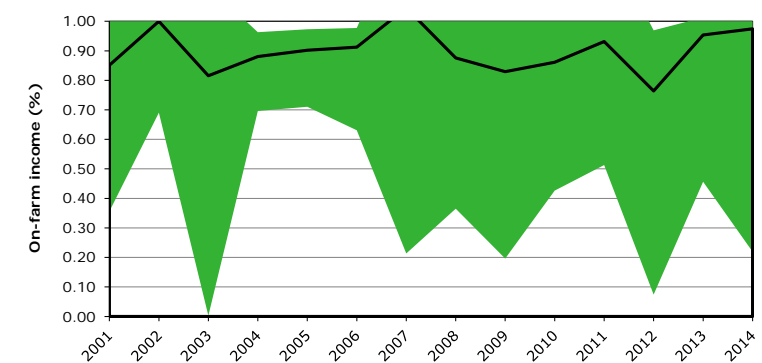

Figure 4.8A Adoption of non-farming income on pig farms (median, P20 and P50).

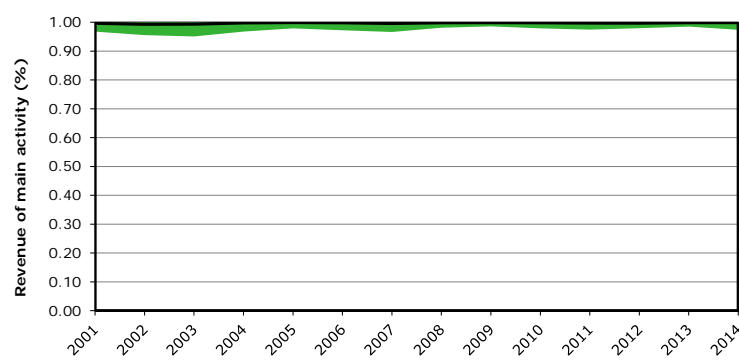

Figure 4.8B Adoption of diversification on pig farms (median, P20 and P50).

\subsection{Risk management strategies in the poultry sector}

Hedging prices is more common in the broiler farming sector than in the laying hen sector (Figure 4.9). Although delivery contracts for one laying period are common in the laying hen subsector, they have been excluded from the analysis since the Innovation Monitor focuses only on price arrangements. 
The level of price protection is limited since the contracted price follows a volatile benchmark. Farm size was not significantly different between price contracts adopters and non-adopters within the subsectors of laying hen farms and broiler farms (T-test and in terms of SO). Since only limited number of poultry farmers within each subsector have contracted (part of) there production the estimation of its impact on price volatility is hampered with FADN.

Besides price, also quality standards and delivering data are specified in the contract of which a flexible delivery date is most common.
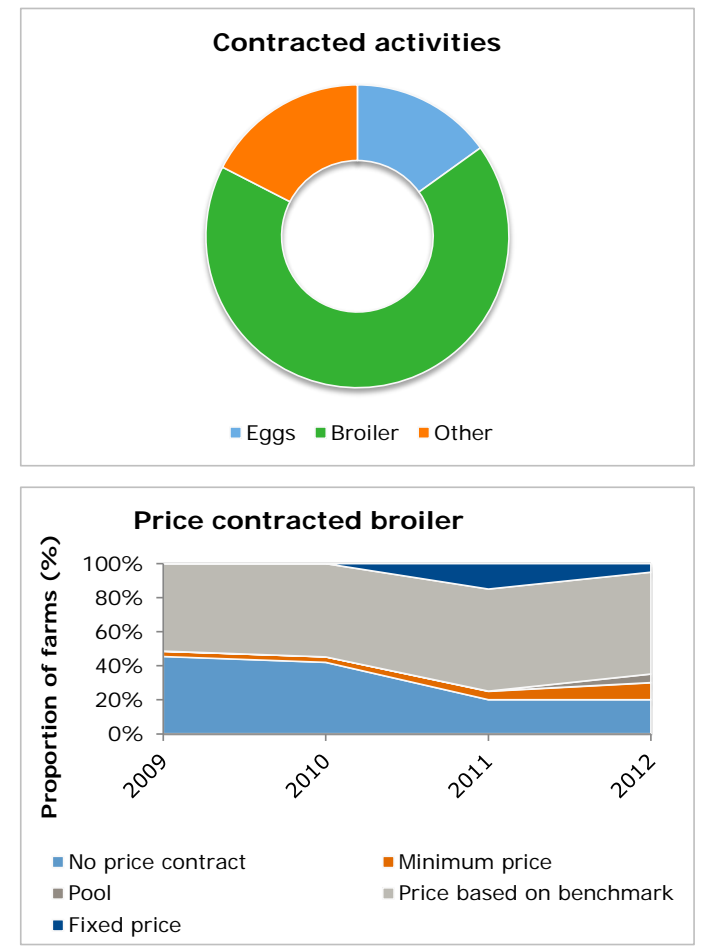

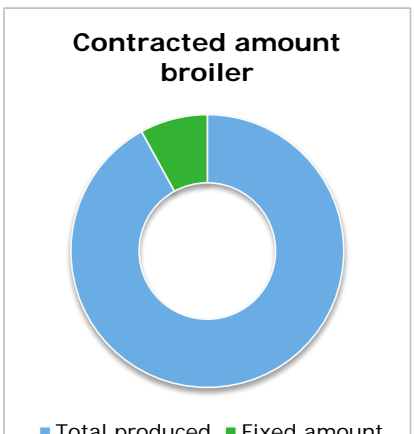

$\backsim$ Total produced $n$ Fixed amount

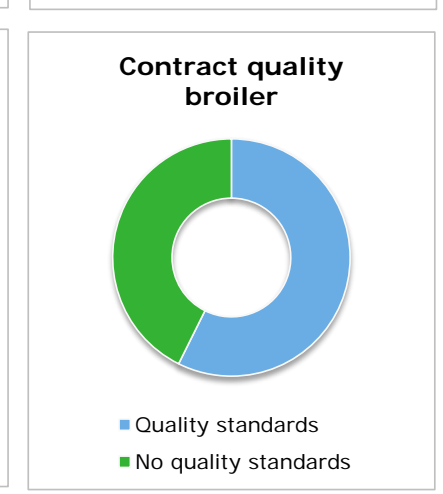

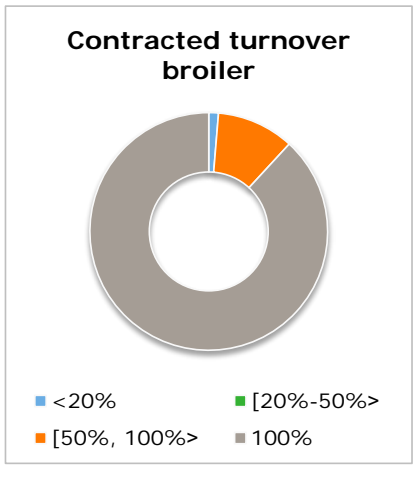

Delivery date broiler

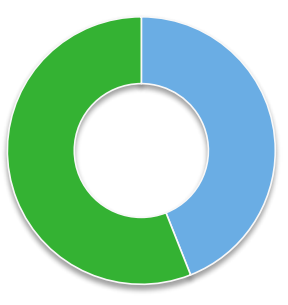

- Fixed delivery date - Flexible delivery date

Figure 4.9 Adoption of price contracts on poultry farms.

On specialised poultry farms, the amount of off-farm income is limited (Figure 4.10). Over the analysed time period, $95 \%$ of the household income stemmed from farming activies, and the remaining $5 \%$ originated from non-farming. Poultry farms with relative more off-farm income did not significantly differ in farm size (T-test and in terms of SO).

Over the analysed time period $97 \%$ of the family farm income stemmed from one either poultry meat or eggs, and the remaining $3 \%$ originated from other farming activities.

In adverse farming years, the proportion of other on-farm or non-farming income increased, but remains very limited in absolute values, and thus provides for the majority of arable farmers limited scope to cope with adverse farming years.

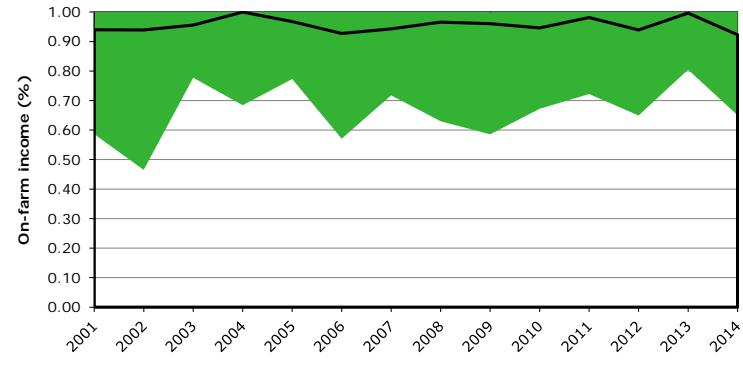

Figure 4.10A Adoption of non-farming income on poultry farms (median, P20 and P50).

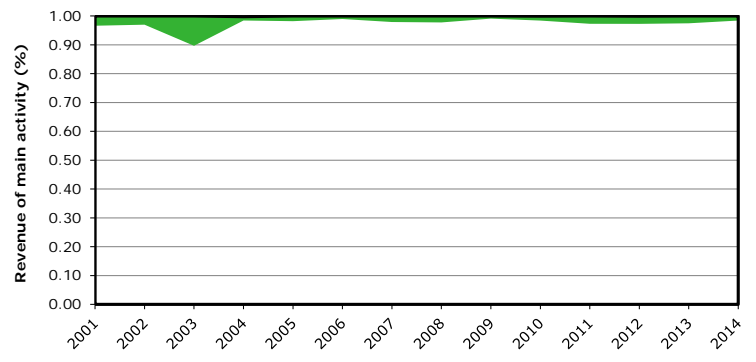

Figure 4.10B Adoption of diversification on poultry farms (median, P20 and P50). 


\section{Conclusions}

\subsection{Volatility and resilience}

Instability of agricultural markets and fluctuations of prices received by farmers are major reasons causing volatile family farm incomes. As illustrated in this report there are large differences in volatility between sectors in the period 2001-2014. The granivore sector (pigs and poultry) and the greenhouse horticulture sector are sectors with the largest fluctuations in family farm incomes (median CV values of $193 \%, 189 \%$ and $139 \%$ respectively). Volatility in family farm income was relatively low in the arable sector (median CV values of $75 \%$ ). In the dairy sector family farm income was even more smoothened (median CV values of $60 \%$ ), but projections are that now the EU milk quota system has been abolished dairy farmers are becoming more exposed to the world market for dairy products and are becoming more vulnerable to (supply and demand) shocks affecting world dairy markets and prices.

The quantitative analyses within each (sub)sector revealed that there is substantial heterogeneity between farms within the same type of farming system with respect to the level of family farm income, and corresponding CV values. More specifically, there is only a limited association between farm size and family farm income volatility in most of the sectors and subsectors analysed (i.e., arable, dairy, pigs and poultry).

Furthermore, the possibilities between sectors to cope with the occurrence of external events differ strongly. Heterogeneity of financial resilience in terms of farm cash flows was profound between (sub)sectors and farms, with the greenhouse horticulture sector, pig sector and poultry sector most vulnerable. An external event such as a decrease in revenues would only worsen the situation. Sectors most vulnerable are also those sectors with the highest family farm income volatility. Note that when a business records a low income from business operations, this does not always need to pose an immediate threat to the continuity of the business. When one-off disappointing results are recorded, the entrepreneur can absorb cash flow shortages with the liquid assets accrued in the prosperous years. Moreover, a low or negative income does not necessarily imply that the cash flow is inadequate, as the costs include depreciation which is not a cash flow and replacement investments might be deferred (www.agrimatie. nl). If greater adjustments are needed to absorb the deficit, an option is to sell parts of the business. The solvency rate of businesses can also be used as a proxy to determine the level of resilience of a farm. The solvency rate indicates the proportion of equity in the total assets. Sectors most vulnerable are also those sectors with the lowest solvency rate (mean solvency rate in 2014 for pig farms, poultry farms and greenhouse horticulture farms are 51\%, 52\% and 46\%, versus $75 \%$ for arable farms and $67 \%$ for dairy farms).

\subsection{Adoption and impact of risk management strategies}

Adoption and impact of risk management strategies to cope with income volatility in agriculture differs between sectors analysed. Uptake of price contracts is a common practice applied on Dutch arable farms. In all other sectors analysed, the availability and uptake of price contracts has hardly been established. Despite free market conditions and volatile prices in most sectors (i.e., pigs, poultry and horticulture, and as the EU dairy sector is now emerging into a more free market situation), the market has not evolved over time in offering farmers effective price contracts.

Approximately $50 \%$ of the Dutch arable farmers have some kind of potato price contract of which the pool contracts and fixed price contracts are the most common ones. Those arable farms that adopted potato price contracts were on average significantly $25 \%$ larger. 
The level of potato price protection depends on the type of price contract and hedged amount. The median potato price volatility was lower on farms with potato price contracts. On arable farms the median CV values for ware potato prices were $19 \%$ on farms without a contract and $15 \%$ with (any kind of) price contract. Note that in the period 2009-2012 with price contract information, no sharp price drop was observed, hence the potential impact of underwriting price contracts is underestimated.

Yet on farm level this impact on CV values was mostly absent. Note that the merit of price contracts cannot be assessed without considering the potential impact on the risk-efficiency of net returns from the whole farm portfolio. The availability of price contracts opens opportunities to engage other risks (i.e., specialisation or increasing farm size). All we can be sure of is that, if the decisions are taken rationally, the farmer's utility should not go down and would normally remain the same only if he or she found the price instrument unattractive.

In the analysed time period the use of price contracts is stable over time, but also within farms. The adoption of price contracts within farms is analysed by counting the number of years that a given farmer decides to underwrite any type of price contract (Garrido and Zilberman, 2008), and subsequently divided by the number of years the farm is in the panel. For example, for the most frequently applied potato price contracts on arable farms, $29 \%$ adopted a price contract each year (during the period 2009-2012), while 40 never hedged prices. Similarly, in poultry farming $38 \%$ adopted a price contract each year, while 26 never applied price contracts (note that price protection for these poultry contracts is limited since the contracted price follows a volatile benchmark).

On average, and in relative terms, off-farm incomes as a risk management strategy smoothens household income only limited for analysed specialised farms with at least $67 \%$ of the standard gross margin originated from the main activity. Association between farm size and off-farm income is sector specific. Arable farms and dairy farms with a relative high off-farm income (above median level) were $37 \%$ and $18 \%$ smaller. Yet, pig farms and poultry farms with relative more off-farm income did not significantly differ in farm size.

Furthermore, diversification is limited applied on specialised farms. Of the analysed sectors, only arable farms widely apply diversification as a risk management tool (which is inherent because of agronomic constraints). Those arable farms that adopted more specialisation (above median level) were on average $46 \%$ larger.

In summary, answering the key question 'Do the analysed risk management strategies reduce price volatility?' is context specific. In general, risk management strategies enable to smoothen or enhance income in the farming sectors. The availability of effective risk management strategies (e.g. price contracts for potatoes) opens opportunities for farmers to engage other risks (i.e., specialisation or increasing farm size). Effective strategies that reduce price risks will ultimately increase farmers' utility (which does not necessarily manifests itself in a reduced CV of farm income). 


\section{References}

Anderson, J. (2003). Risk in Rural Development: Challenges for Managers and Policy Makers, Agricultural Systems 75, No. 2-3: pp. 161-197.

Berentsen, P.B.M., K. Kovacs and M.A.P.M. van Asseldonk, (2012). Comparing risk in conventional and organic dairy farming in the Netherlands: an empirical analysis. J Dairy Sci 95:3803-3811.

Berentsen, P.B.M. and M.A.P.M. van Asseldonk, (2016). An empirical analysis of risk in conventional and organic arable farming in the Netherlands. Submitted for publication.

Dolman, M.A., H.C.J. Vrolijk and I.J.M. de Boer (2012). Exploring variation in economic, environmental and societal performance among Dutch fattening pig farms. Livestock Science, 149(1-2), 143- 154

Diederen, P., H.V. Meijl, A. Wolters and K. Bijak (2003). 'Innovation adoption in agriculture : innovators, early adopters and laggards.' Cahiers d'Economie et de Sociologie Rurales (CESR) 67.

Garrido, A.M., and D. Zilberman (2008). Revisiting the Demand for Agricultural Insurance: The Case of Spain. Agricultural Finance Review 68(1):43-66.

Holling, C.S. (1973). Resilience and stability of ecological systems. Annual Review of Ecology and Systematics, 4, 1-23.

Keane, M. and D. O'Connor, (2009). Association Price Volatility in the EU Dairy Industry: Causes, Consequences and Coping Mechanisms. Report Prepared for the European Dairy.

Lans, T., M.A. van Galen, J.A.A.M. Verstegen, H.J.A. Biemans and M. Mulder (2014). 'Searching for entrepreneurs among small business ownermanagers in agriculture.' NJ AS - Wageningen Journal of Life Sciences 68: 41-51.

Pennings, J.M.E., P. Garcia and A.J. Oskam (2010), 'Private Market and Price Stabilization Methods', in EU Policy for Agriculture, Food and Rural Areas, eds. A.J. Oskam, G. Meester and H. Silvis, pp. 181-187 (ISBN: 978-90-8686-118-7), Wageningen Academic Publishers, Wageningen, The Netherlands.

J ongeneel, R. and S. van Berkum, 2015. What will happen after the EU milk quota system expires in 2015? An assessment of the Dutch dairy sector. Wageningen, LEI Wageningen UR (University \& Research centre), LEI Report 2015-041.

Vrolijk, H. and K. Poppe (2008). Income volatility and income crises in the European Union. In: Meuwissen, M., K. van Asseldonk and H. Huirne, Income stabilisation in European agriculture: Design and economic impact of risk management tools. Wageningen Academic publishers, Wageningen.

Vrolijk, H.C.J., C.J.A.M. de Bont, H.B. van der Veen, J.H. Wisman and K.J. Poppe (2009). Volatility of farm incomes, prices and yields in the European Union. Report 2009-005, LEI Wageningen UR, The Hague.

Vrolijk, H.C.J., H.B. van der Veen, J.P.M. van Dijk (2010). Sample of Dutch FADN 2008; Design principles and quality of the sample of agricultural and horticultural holdings. LEI Wageningen UR, The Hague.

Smidts, A. (1990). Decision making under risk. A study of models and measurement procedures with special reference to the farmers' marketing behavior. Dissertation. Wageningen Economic Studies no. 18, Pudoc, Wageningen (329p). 
LEI Wageningen UR

\section{P.O. Box 29703}

2502 LS The Hague

The Netherlands

$\mathrm{T}+31(0) 703358330$

E publicatie.lei@wur.nl

www.wageningenUR.nl/en/lei

REPORT

LEI 2016-054
LEI Wageningen UR is one of the world's leading independent socio-economic research institutes. LEl's unique data, models and knowledge offer clients insight and integrated advice on policy and decision-making in an innovative manner, and ultimately contribute to a more sustainable world. LEI is part of Wageningen UR (University and Research centre), forming the Social Sciences Group together with the Department of Social Sciences and Wageningen UR Centre for Development Innovation.

The mission of Wageningen UR (University \& Research centre) is 'To explore the potential of nature to improve the quality of life'. Within Wageningen UR, nine specialised research institutes of the DLO Foundation have joined forces with Wageningen University to help answer the most important questions in the domain of healthy food and living environment. With approximately 30 locations, 6,000 members of staff and 9,000 students, Wageningen UR is one of the leading organisations in its domain worldwide. The integral approach to problems and the cooperation between the various disciplines are at the heart of the unique Wageningen Approach. 



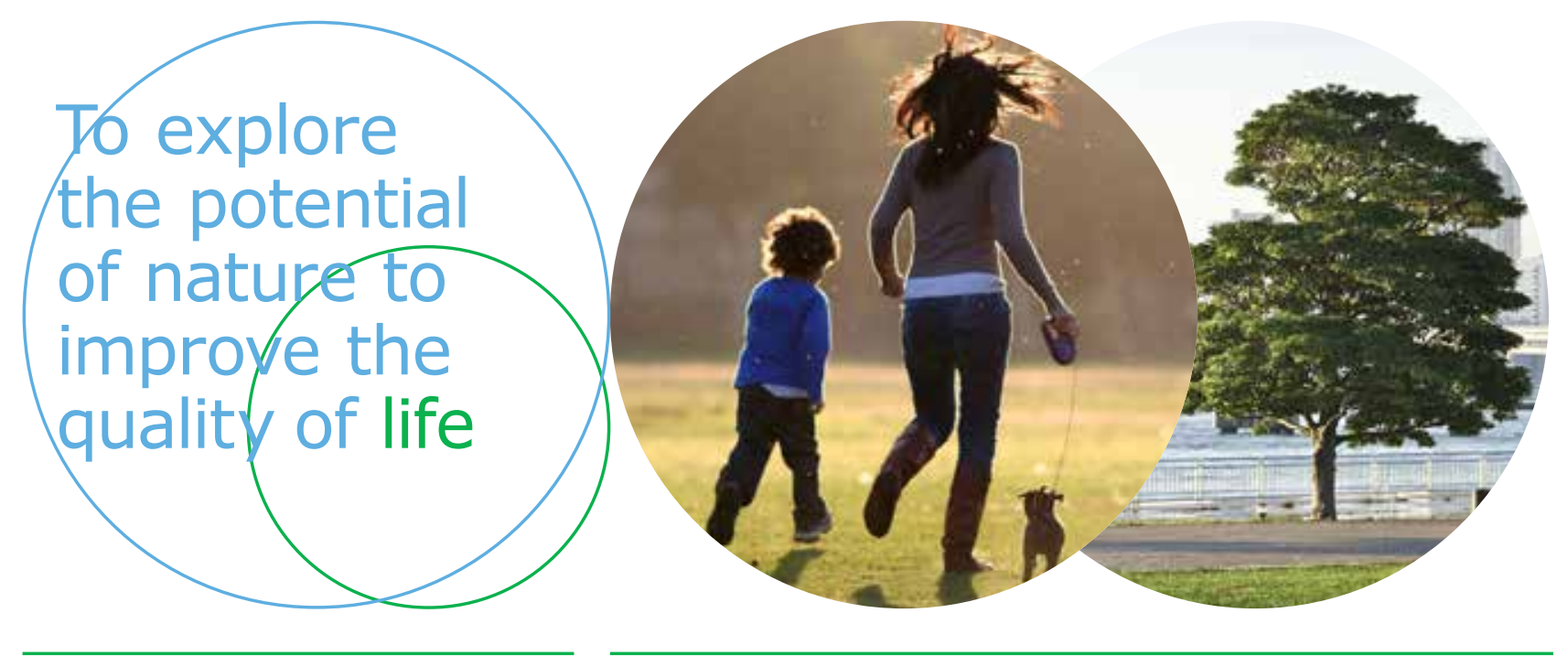

LEI Wageningen UR

P.O. Box 29703

2502 LS Den Haag

The Netherlands

E publicatie.lei@wur.nl

www.wageningenUR.nl/lei

REPORT

LEI 2016-054

ISBN 978-94-6257-824-1
LEI Wageningen UR is one of the world's leading independent socio-economic research institutes. LEI's unique data, models and knowledge offer clients insight and integrated advice on policy and decision-making in an innovative manner, and ultimately contribute to a more sustainable world. LEI is part of Wageningen UR (University and Research centre), forming the Social Sciences Group together with the Department of Social Sciences and Wageningen UR Centre for Development Innovation.

The mission of Wageningen UR (University \& Research centre) is 'To explore the potential of nature to improve the quality of life'. Within Wageningen UR, nine specialised research institutes of the DLO Foundation have joined forces with Wageningen University to help answer the most important questions in the domain of healthy food and living environment. With approximately 30 locations, 6,000 members of staff and 9,000 students, Wageningen UR is one of the leading organisations in its domain worldwide. The integral approach to problems and the cooperation between the various disciplines are at the heart of the unique Wageningen Approach. 